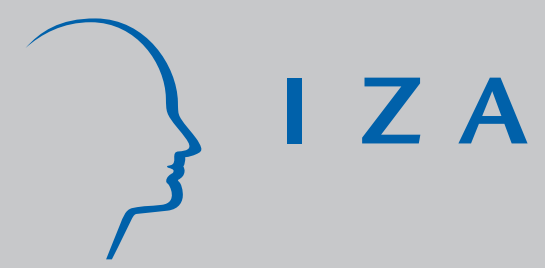

IZA DP No. 7759

After the Tournament: Outcomes and Effort Provision

Andrew McGee

Peter McGee

November 2013

Forschungsinstitut

zur Zukunft der Arbeit

Institute for the Study

of Labor 


\title{
After the Tournament: Outcomes and Effort Provision
}

\author{
Andrew McGee \\ Simon Fraser University \\ and IZA \\ Peter McGee \\ National University of Singapore
}

Discussion Paper No. 7759

November 2013

\author{
IZA \\ P.O. Box 7240 \\ 53072 Bonn \\ Germany \\ Phone: +49-228-3894-0 \\ Fax: +49-228-3894-180 \\ E-mail: iza@iza.org
}

Any opinions expressed here are those of the author(s) and not those of IZA. Research published in this series may include views on policy, but the institute itself takes no institutional policy positions. The IZA research network is committed to the IZA Guiding Principles of Research Integrity.

The Institute for the Study of Labor (IZA) in Bonn is a local and virtual international research center and a place of communication between science, politics and business. IZA is an independent nonprofit organization supported by Deutsche Post Foundation. The center is associated with the University of Bonn and offers a stimulating research environment through its international network, workshops and conferences, data service, project support, research visits and doctoral program. IZA engages in (i) original and internationally competitive research in all fields of labor economics, (ii) development of policy concepts, and (iii) dissemination of research results and concepts to the interested public.

IZA Discussion Papers often represent preliminary work and are circulated to encourage discussion. Citation of such a paper should account for its provisional character. A revised version may be available directly from the author. 
IZA Discussion Paper No. 7759

November 2013

\section{ABSTRACT}

\section{After the Tournament: Outcomes and Effort Provision}

Modeling the incentive effects of competitions among employees for promotions or financial rewards, economists have largely ignored the effects of competition on effort provision once the competition is finished. In a laboratory experiment, we examine how competition outcomes affect the provision of post-competition effort. We find that subjects who lose arbitrarily decided competitions choose lower subsequent effort levels than subjects who lose competitions decided by their effort choices. We explore the preferences underlying this behavior and show that subjects' reactions are related to their preferences for meritocratic outcomes.

JEL Classification: $\quad$ C90, J30, D03

Keywords: tournaments, counterproductive behavior, promotions, experiment

Corresponding author:

Peter McGee

Department of Economics

National University of Singapore

1 Arts Link

Singapore, 117570

Singapore

E-mail: ecspjm@nus.edu.sg 


\section{Introduction}

Firms in some instances use competition among workers for bonuses and promotionstournaments — to elicit optimal effort levels when effort is not fully contractible. The widespread usage of tournaments as an incentive mechanism has generated commensurate interest among economists: the extensive economics literature on tournaments has explored the effects of sabotage, prize and tournament structure, participant feedback, multiple contests, and other aspects of tournament design on effort provision (e.g., Schotter and Weigelt 1992; Tong and Leung 2002; Carpenter et al. 2010; Harbring and Irlenbusch 2011; Altmann et al. 2012). Tournament models to date, however, overlook an important-and fundamental—feature of actual promotion tournaments: the end of the tournament is rarely the end of the road.

In practice, tournament participants typically continue to exert effort on behalf of the firm after the tournament has concluded, allowing the tournament outcome to influence the posttournament workplace. Industrial/organizational psychologists have documented so-called “counterproductive workplace behaviors” (CWBs)—defined as "volitional acts that harm or are intended to harm organizations or people in organizations” (e.g., Bennett \& Robinson 2000; Dunlop \& Lee 2004; Fox \& Spector 2004; Markus \& Shuler 2004; Mount \& Johnson 2006)— ranging from increased dislike of coworkers to increased absenteeism and production sabotage following unfavorable promotion outcomes (Schaubroeck and Lam 2004; Schwarzwald et al. 1992). All of these studies likely understate the importance of CWBs because they rely on selfreports of CWBs. In this study, we use a laboratory experiment-which allows us to directly measure behavior analogous to CWBs in the form of effort reductions - to investigate whether and when tournament outcomes influence the post-tournament effort decisions of winners and 
losers and to provide evidence concerning the nature of the preferences that could rationalize the links we observe between tournament outcomes and post-tournament effort decisions.

We compare behavior in four treatments requiring subjects to make effort choices both during and after a tournament contest. Subjects in our primary treatment participated in $\mathbf{4 0}$ periods and were paired with a new subject in each period. In each period, subjects first competed in a tournament in the Lazear and Rosen (1981) mold and then participated in a noncompetitive production stage. In both the tournament and production stages, subjects chose a costly level of effort that was converted into output through a known production process with a stochastic element. In "rule-based" tournaments, the partner with the higher output won and was awarded a higher payment than the loser. A quarter of all tournaments, however, were "random outcome” tournaments in which the outputs of the partners were disregarded and the winner determined arbitrarily with each partner having equal probability of winning. Subjects did not know whether a tournament was a "rule-based" or "random outcome" tournament until after they made their tournament effort choices. In the production stage, subjects knew both the results of the tournament and how the tournaments had been decided before making their costly effort choices. All subjects in the production stage earned one-third of their production stage output; the tournament winner also received one-fifth of the tournament loser's production stage output.

We introduce the "random outcomes" to allow subjects to feel "hard done by" on occasion in a tournament as feelings or perceptions of injustice have been shown to predict the emergence of CWBs (Skarlicki \& Folger, 1997; Acquino, Lewis, and Bradfield 1999; Skarlicki, Folger, \& Telsuk 1999; Martinko, Gundlach, \& Douglas 2002; Flaherty \& Moss 2007; Jones 2009). In particular, perceptions of injustice may result from failure to win a promotion. Schwarzwald et al. (1992) find that workers perceived more inequity when they voluntarily 
submitted their candidacy for promotion but were unsuccessful, and this sense of inequity was associated with a decreased commitment to the firm and more lateness and absenteeism among non-promoted workers. Similarly, Schaubroeck and Lam (2004) find that employees who were not promoted experienced increased feelings of envy toward those who were promoted. This envy resulted in promoted employees being rated as less likeable following the promotion than before the promotion—an effect that was strongest when the non-promoted worker judged the promotee to be similar to himself. Both studies suggest that tournaments may result in counterproductive behaviors when workers feel they had a good case for winning but lose.

Across treatments, we find that some subjects choose high effort levels regardless of whether they are choosing effort to win a tournament or to produce output in order to be paid at a piece rate. As such, tournaments tend to select "high effort" subjects as winners. Controlling for this individual heterogeneity, we find that tournament outcomes have a significant influence on production stage effort choices only when the tournament is randomly decided. Subjects who lose in random outcome tournaments but who would have also lost in rule-based tournaments choose effort levels that are seven percent lower than the mean effort of tournament losers; subjects who lose in random outcome tournaments but would have won in rule-based tournaments choose effort levels that are thirteen percent lower than the mean effort of tournament losers. We see similar production stage effort reductions in a treatment pairing tournament winners and losers with new partners in the production stage, indicating that the effort reduction is not aimed directly at a rival. We do find evidence, however, that effort reductions following arbitrarily decided tournaments may be a "hot state" reaction as subjects appear to withdraw effort only in the short run in a treatment in which a tournament is followed by multiple production stages with the same partner. Using survey instruments, we find that the 
effort reductions in response to losing a randomly decided tournament are correlated with subjects' preferences for merit-based outcomes. Losers who feel that outcomes should reflect their effort choices reduce their post-tournament effort more than other subjects when the tournament outcome disregards effort choices.

Our study makes three important contributions to economists' understanding of the incentive effects of tournaments and competition more generally. First, our findings highlight the uncomfortable reality for firms that perceptions of promotion contests count. If workers believe a promotion contest to have been arbitrary, capricious, or unfair, they may exert less effort subsequently than had they lost "fair and square." In the extreme, the industrial psychology literature suggests that workers who perceive a firm's actions to be unfair may actively seek to harm the organization (Fox and Spector 2004). As such, it is in the interest of firms to promote transparency and objectivity when deciding promotion contests to avoid such grievances. Second, our findings indicate that tournaments are effective mechanisms for identifying individuals who exert high levels of effort in a variety of circumstances. If the productivity of a worker in a post-tournament firm is important—as presumably it is in most instances—-then tournaments will be effective screening mechanisms. Finally, our study indicates that personality and preferences are related to post-tournament behavior. Taken together, these findings highlight the importance of the non-monetary factors that motivate employees' behavior-namely personality, preferences, and perceptions—-for the design of incentive schemes.

\section{Related Literature}

A comprehensive review of the experimental literature concerning tournaments can be found in Dechenaux, Kovenock, and Sheremeta (2012), but a few studies are particularly relevant. Average tournament effort choices in the laboratory have been shown to be close to the 
equilibrium effort level when players are symmetric and a pure-strategy Nash equilibrium exists; there is, however, a great deal of variation in effort choices such that the predictions concerning effort levels hold only in the aggregate (Bull et al. 1987; Schotter and Weigelt 1992; Nalbanthian and Schotter 1997). We find that some subjects are prone to choosing high effort levels and others low effort levels across different incentive environments. This subject-level heterogeneity may explain why the theoretical predictions hold only on average.

A few studies examine multi-stage tournaments in which subjects make a series of effort choices in order to win the tournament. Tong and Leung (2002) had subjects submit effort levels over successive stages; subjects with the highest realized output summed over all stages won the tournament. They find that total effort levels were significantly higher in these dynamic tournaments than in strategically equivalent, one-stage tournaments. Similarly, Altmann et al. (2012) find that first stage effort in a two-stage tournament was significantly higher than the equilibrium first stage effort level and higher than the observed effort level in a strategically equivalent, one-stage tournament—overprovision of effort possibly driven by subjects who derive utility from winning or who engage in an insufficient amount of forward thinking. In the Altman et al. study and in our experiment, subjects' first stage effort choices reflect the option value of winning, but our study differs from both the Tong and Leung and Altman et al. experiments in that the production stage effort choice is strategically independent of the tournament effort choice if a subject is profit-maximizing. There are multiple effort choices to be made in our experiment, but one is clearly after the tournament ends.

Preferences for "fairness" have been incorporated into tournament models. Grund and Sliwka (2005) show that more inequality-averse agents—agents who dislike unequal outcomes but prefer having more than others to having less than others (Fehr and Schmidt 1999, Bolton 
and Ockenfels 2000)—will exert higher effort in tournaments than less inequality-averse agents to avoid losing and ending up with a lower payoff than others. Such difference aversion models, however, cannot account for reciprocity or "intentions" concerns, a shortcoming that has given rise to models incorporating both the intentions of one's counterparty and payoff inequality (e.g., Rabin 1993; Dufwenberg and Kirchsteiger 2004; Charness and Rabin 2005; Falk and Fischbacher 2003). None of these models can provide a sufficient explanation for our findings concerning how subjects react to tournament outcomes. Distributional concerns may be drivers of CWBs, but the responses to tournament outcomes that we observe-in particular the reduction in production stage effort by tournament losers in randomly-decided tournaments—would only exacerbate income differences. Likewise, the intentions of one's peers or organization may result in CWBs in practice, but the capriciousness of the randomly decided tournaments to which subjects react in our experiment is independent of any subject's actions or intentions.

For this reason, we investigate whether procedural fairness concerns drive reactions to tournament outcomes by examining the correlation between subjects' measured preferences for meritocratic outcomes and responses to random tournament outcomes. Procedural fairness concerns have been shown to be related to decisions in the battle-of-the-sexes and ultimatum games (Bolton et al. 2005). Unfair allocations - those in which one player receives almost all the pie and the other almost nothing — were found to be more acceptable to subjects when implemented by an unbiased random procedure that assigned equal probabilities to both the unfair and the fair allocations than when the unfair allocation was chosen by another subject. When an unfair allocation was implemented by a random procedure that was biased towards the unfair allocation, however, subjects found this no more acceptable than if the unfair allocation had been chosen by another subject. By contrast, we find that subjects’ effort choices respond to 
capricious outcomes even though the random procedure occasionally determining tournament outcomes is unbiased, which suggests that procedural fairness concerns may operate differently when subjects condition choices on prior effort and outcomes.

The notion that competitors' assessments of outcomes are a function of their effort decisions has been incorporated into tournament models. Kräkel (2008) models "emotional” agents who feel either pride when outperforming others in a tournament or disappointment when failing to do so. Similarly, Gill and Stone (2010) model agents who value getting their "just deserts" in a tournament. Their agents do not measure themselves against others in the tournament; rather they have an expectation about what they ought to get out of a tournament based on their own efforts. While these models incorporate the notion that competitors care about tournament outcomes themselves in addition to the monetary rewards attached, none consider how such preferences influence effort choices after the tournament.

Most closely related to ours is the study by Gill and Prowse (2012a) who examine how tournament outcomes affect subsequent tournament effort choices in a laboratory experiment. They find substantial gender differences in how men and women react to tournament losses: women on average reduce their effort in tournaments following a loss while men reduce their effort only in response to losing a large prize. Several design differences limit the direct comparability of their results and ours. Among others, subjects in their experiment complete a real effort task, make effort decisions sequentially such that the "second mover" knows how many tasks the "first mover" has completed before starting the tasks, and face no capricious outcomes. ${ }^{1}$ The crucial difference between the two studies, however, is that we are observing reactions to tournament outcomes in a completely non-strategic setting. While tournament effort

\footnotetext{
${ }^{1}$ Gill and Prowse (2012b) shows that subjects exhibit "disappointment aversion” insofar as secondmovers facing a rival who expended significant effort exerted less effort to avoid feeling disappointment should they lose, reinforcing the notion that subjects care about the outcomes themselves.
} 
choices might reasonably be informed by success or failure in previous tournaments, subjects paid according to a piece-rate in our production stage have no reason to condition production stage effort choices on tournament outcomes. That tournament outcomes affect effort choices after the tournament concludes has profound implications for the design of incentive schemes.

\section{Tournament Model}

We consider a two-stage model consisting of a tournament stage and a post-tournament production stage. In the tournament stage, two workers compete by choosing a costly effort level (e) to produce noisy output $(Y)$ as in Lazear and Rosen (1981). Output is given by the production function $Y=a e+\varepsilon$, where $\varepsilon$ is a random component of output with mean zero and variance $\sigma^{2}$. The cost of effort is given by $C(e)$ where $C^{\prime}>0$ and $C^{\prime \prime}>0$.

In most cases, the tournament is won by the worker who produces more output. With known probability $\mu$, however, the winner of the tournament is determined randomly with each competitor being equally likely to win. Competitors make their effort choices before learning whether the outcome of the tournament will be decided based on the output rule or by chance. The tournament winner receives payment $W$, while the loser receives $L(W>L)$.

In the production stage, the costs of effort and the production function are the same as in the tournament. Each worker chooses effort to produce output and is paid according to a piece rate, $\alpha Y$. In addition, the tournament winner receives a fraction $\beta$ of the tournament loser's production stage output, $Y_{P}^{L}$. In the context of an organization, the tournament stage represents the competition for a promotion and the production stage what happens when former rivals take up their new positions in the corporate hierarchy. The payment of $\beta Y_{P}^{L}$ to the tournament winner reflects the fact that the performance of a manager's subordinates influences his pay. 
The production stage payoffs to the tournament winner and loser are $\alpha Y_{P}^{W}+\beta Y_{P}^{L}$ and $\alpha Y_{P}^{L}$, respectively. The profit-maximizing production stage effort levels are the same for both players given that they have the same production and cost functions. Denote this profitmaximizing effort level as $e^{*}$ and the expected production stage profits for tournament winners and losers as $E \pi_{W}^{*}$ and $E \pi_{L}^{*}$. Given these expected payoffs in the production stage, the workers $(i=1,2)$ choose effort levels $\left(e_{i}\right)$ in the tournament stage to maximize their expected earnings ${ }^{2}$ :

$$
\mu\left[\frac{1}{2}\left(W+E \pi_{W}^{*}\right)+\frac{1}{2}\left(L+E \pi_{L}^{*}\right)\right]+(1-\mu)\left[P\left(e_{i}\right)\left(W+E \pi_{W}^{*}\right)+\left(1-P\left(e_{i}\right)\right)\left(L+E \pi_{L}^{*}\right)\right]-C\left(e_{i}\right)
$$

The probability of winning conditional on effort $e_{i}, P\left(e_{i}\right)$, is given by

$$
P\left(e_{i}\right)=\operatorname{prob}\left(Y_{i}>Y_{j}\right)=\operatorname{prob}\left(e_{i}-e_{j}>\frac{\varepsilon_{j}-\varepsilon_{i}}{a}\right)=G\left(e_{i}-e_{j}\right)
$$

where $G(\cdot)$ is the cumulative distribution function of $\xi=\left(\frac{\varepsilon_{j}-\varepsilon_{i}}{a}\right)$. The first-order condition for each worker $i$ is given by

$$
\frac{\partial P}{\partial e_{i}}(1-\mu)\left(W+E \pi_{W}^{*}-L-E \pi_{L}^{*}\right)-C^{\prime}\left(e_{i}\right)=0
$$

where $\frac{\partial P}{\partial e_{i}}=g\left(e_{i}-e_{j}\right)$. The second order condition for each worker $i$ is given by

$$
\frac{\partial^{2} P}{\partial e_{i}^{2}}(1-\mu)\left(W+E \pi_{W}^{*}-L-E \pi_{L}^{*}\right)-C^{\prime \prime}\left(e_{i}\right)<0
$$

The second-order condition must be satisfied to guarantee the existence of a symmetric Nash equilibrium in pure strategies (Lazear and Rosen 1981). The parameter values in our experiment are such that the second-order condition is not satisfied, and no pure strategy equilibrium exists - a design decision we explain in the next section.

The mixed strategy equilibrium follows from the proof of Proposition 3 in Che and Gale (2000); details are provided in the Appendix. Agents in a symmetric mixed-strategy equilibrium

\footnotetext{
${ }^{2}$ Sheremeta and $\mathrm{Wu}$ (2011) model tournaments with risk-averse agents to rationalize laboratory findings inconsistent with risk-neutral agents. We follow the convention of assuming risk-neutral agents.
} 
randomize over effort levels that are multiples of $\delta$ in the interval $[0, \bar{e}]$, where the probability that an effort level is chosen is a strictly increasing function of the marginal cost of that effort level. The largest effort level in the support, $\bar{e}$, is determined by the expected value of winning the tournament and varies across treatments. ${ }^{3}$

\section{Behavioral Hypotheses and Experimental Details}

The model's equilibrium predictions provide a useful benchmark for our expectations concerning behavior, but the organizational psychology literature concerning reactions to adverse promotion outcomes leads us to suspect that behavior will reflect preferences not captured in the benchmark model—particularly for post-tournament effort choices. Specifically, we hypothesize that subjects will respond to capricious tournament losses—losses determined by factors other than effort—by reducing their effort. We further hypothesize that capricious tournament outcomes and post-tournament effort might be related for three reasons. First, effort reductions may be directed at one's tournament counterparty. In a two-person contest, if capriciousness works against one party, it necessarily works in favor of the other. This effect might be magnified in a firm where tournament outcomes affect payouts and subsequent hierarchical relationships. Second, effort reductions may be a visceral, emotional reaction to the tournament outcome that fades with time. Reducing one's effort at work or engaging in some other sort of CWB may serve as a catharsis, but engaging in CWBs over time also makes it more likely that one will be fired. Finally, effort reductions may reflect distaste for arbitrary tournament outcomes when a (noisy) measure of effort is available. This is perhaps the most

\footnotetext{
${ }^{3}$ The interval between points in the support of the equilibrium mixed strategy, $\delta$, is a function of the distribution of the noisy component of output $\varepsilon$. As the variance of $\varepsilon$ decreases, $\delta$ gets smaller such that $\delta \rightarrow 0$ as $\sigma^{2} \rightarrow 0$. Without noise in the output, players would randomize over every effort level in [0, $\left.\bar{e}\right]$ as described above in the mixed strategy equilibrium (see the appendix in Nalebuff and Stiglitz (1983) for the derivation of the mixed strategy equilibrium when $\sigma^{2}=0$ ). Given that the noise in output is very small in our experiment, we expect subjects to essentially randomize over all effort levels in $[0, \bar{e}]$.
} 
familiar workplace scenario: a worker feels that—in spite of his hard work—a promotion was awarded to an undeserving coworker and subsequently chooses, for example, not to work late to protest this decision. The experimental treatments described below investigate whether there exist links between (capricious and non-capricious) tournament outcomes and post-tournament effort decisions and whether the potential explanations for adverse reactions to tournament outcomes described above find support in the data.

A total of 148 undergraduate subjects at Simon Fraser University participated in one of four treatments: the linked payoff treatment (LP), the "rotating manager" treatment (RM), the repeated production stage treatment (RPS), and the baseline treatment (BL). Table 1 summarizes the sessions, which lasted about two hours. The instructions to subjects for all four treatments and screenshots of the user interface can be found in the Appendix. The experiment is programmed in zTree (Fischbacher 2007).

\section{IV.A Linked Payoff Treatment}

The LP treatment—-the primary treatment of interest—consisted of forty periods broken into two stages each. Subjects were randomly paired with a different subject in each period, and subjects were made aware of this matching procedure in the instructions. At the beginning of each session, subjects were assigned a color, red or blue. In every period, one subject in each pairing was "Red" and the other subject was "Blue." The first stage in each period was the “tournament” stage, while the second stage was the "production” stage.

In the tournament stage, subjects chose "effort" levels $(e)$ between 0 and 6 specified to the nearest hundredth. Effort was converted into output $(Y)$ according to the production function

$$
Y=120 e+\varepsilon
$$


where $\varepsilon$ was drawn from a uniform distribution over the interval $[-2,2]$. The cost of effort to subjects in experimental currency units (ECUs, CD $\$ 1=20$ ECUs) was given by

$$
C(e)=10 e^{2}
$$

Two mechanisms were used to determine the winner of each tournament. In "rule-based" periods, the partner who produced more output in the tournament stage was declared the winner. In "random outcome" periods, the partner of a randomly selected color was declared the winner regardless of the players' outputs. Subjects did not know whether the period would be a "rulebased" or "random outcome" period until after they had selected their tournament effort levels. In the instructions, subjects were informed that in any period there was a $25 \%$ chance the outputs would be disregarded and the winner of the tournament stage would be determined by color. In all periods, subjects learned their output, the other player's output, and the rule-based outcome of the tournament. That is, subjects knew whether the randomness of random outcome periods affected the outcome. Regardless of how the winner of the tournament stage was decided, the winner received a payment of 162 ECUs, while the loser received a payment of 90 ECUs.

After the tournament stage, the partnered subjects entered the production stage in which they again produced output by choosing an effort level. The production function and the costs of effort were the same as in the tournament stage. Subjects had as much time as they wished to use an on-screen calculator to determine what their earnings would be for any level of effort. ${ }^{4}$ All subjects earned one-third of their production stage output less their effort costs, while tournament stage winners also received an amount equal to one-fifth of their partner's output.

Given the production and cost functions, the distribution of the random component of output, the prizes for winners and losers, and the piece-rate, the upper bound on the support of

\footnotetext{
${ }^{4}$ Subjects had access to a calculator in both stages that displayed the cost of any effort level and provided a range in which output would fall for any effort choice.
} 
the equilibrium mixed strategy for the tournament effort level, $\bar{e}$, was 2.11 in this treatment. The expected effort level given the equilibrium mixing probabilities was 1.43. The profit-maximizing effort choice for winners and losers alike in production stages in all treatments was two.

We opted for a tournament in which the random component of output was small relative to total output even though this feature of the design precludes an equilibrium in pure strategies in the tournament stage. This decision ensures that observed responses to random outcomes that differ from rule-based outcomes are responses to the treatment (i.e., the random allocations) in random outcome periods rather than to the vagaries of the random component of output. Although our primary interest is in the effort choice after the tournament, this design also allows us to test a conjecture in Decheneaux et al. (2012). Reviewing the contest literature, Decheneaux et al. point out that subjects overbid on average in experimental all-pay auctions and Tullock contests, but not in experimental tournaments, a difference that may be due to the large noise terms necessary to ensure an equilibrium in pure strategies in tournaments. ${ }^{5}$ Che and Gale (2000) also note that as the noise term approaches zero, the tournament approaches an all-pay auction. If this is the case, the behavior in our tournament with little noise ought to resemble that in an all-pay auction with more overprovision of effort than in other tournament experiments.

At the end of all sessions, subjects completed a questionnaire measuring risk attitudes using the Holt-Laury paired lottery instrument (Holt and Laury 2002), the Big 5 personality traits (Goldberg 1992), optimism-pessimism (Scheirer et al. 1994), locus of control (Rotter 1966), and "preference for merit.” This last scale measures how strongly individuals feel rewards should be

\footnotetext{
${ }^{5}$ Nieken (2010) provides some support for this conjecture by offering subjects a choice of two noise distributions. Theoretically, a risk-neutral agent should prefer the distribution with the higher variance because it lowers the equilibrium effort level, and subjects do choose lower effort levels when this variance is higher. She finds, however, that subjects are less inclined to select the distribution with higher variance when given the choice, resulting in higher average effort choices.
} 
tied to effort (Davey et al. 1999). Subjects were paid for two randomly selected periods and for one randomly selected decision on the Holt-Laury measure.

\section{IV.B Rotating “Manager” Treatment}

The RM treatment proceeds exactly as in the LP treatment in the tournament stage. In the production stage, however, subjects are matched with new partners. Winners in the tournament stage are matched with tournament losers from another pairing and receive one-fifth of their production stage partner's output. The upper bound on the equilibrium effort levels in mixed strategies, $\bar{e}$, was 2.11, while the expected effort was 1.43 . If a subject withholds production stage effort in an attempt to punish the person who benefitted at his expense, we would not expect to see effort reductions in the RM treatment because-as we make sure the subjects are aware-the production stage partner is not the same as the tournament partner.

\section{IV.C Repeated Production Stage Treatment}

The tournament stage of the RPS treatment proceeds exactly as in the LP treatment, but subjects participate in four production stages following every tournament. Every subject receives one third of his output less his costs in each production stage while the tournament winner also receives one fifth of the tournament loser's output in each production stage. Subjects participating in the RPS treatment completed fewer periods (in most sessions 30 periods) because each period was longer. The upper bound on the equilibrium effort levels in mixed strategies, $\bar{e}$, is 3.14 (reflecting the higher expected return to winning the tournament relative to other treatments), while the expected effort is 2.11. If subjects express their frustrations over tournament outcomes in the immediate aftermath of the tournament before “cooling off” and acting in their material best interests, we would expect effort reductions to be smaller with each subsequent production stage following a capricious outcome. 


\section{IV.D Baseline Treatment}

The two stages in the BL treatment proceed exactly as in the LP treatment, but there are no random outcomes and there is no linkage between the tournament and production stages. Subjects receive one-third of their output less their costs in the production stage and nothing else. The upper bound on the equilibrium effort levels in mixed strategies, $\bar{e}$, was 1.88 , while the expected effort was 1.27. The baseline treatment allows us to compare the decisions of losers in the absence of payoff linkages to the decisions of losers when the payoffs in the production stage are linked to tournament stage outcomes.

\section{Findings}

\section{V.A Tournament Effort}

Our focus is on effort provision after and in response to the tournament, but tournament effort choices and the resulting outcomes shape the post-tournament environment. If aggregate subject behavior approximates the mixed strategy equilibrium, then higher effort levels should be chosen more frequently up to $\bar{e}$. Figure 1 presents kernel density plots of the tournament stage effort choices across treatments. The empirical distributions of tournament effort choices are qualitatively similar to those we would expect if subjects adhered to the mixed strategy equilibrium: more costly effort levels are chosen more frequently up to a point beyond which higher effort levels are chosen very infrequently. Nevertheless, subjects overprovide effort: the average (predicted) tournament efforts reported in table 2 in the BL, LP, RM, and RPS treatments were $1.79(1.27), 2.34(1.43), 2.21(1.43)$ and $3.47(2.11)$, respectively. The $75^{\text {th }}$ percentiles of the observed effort choices in these treatments were 2.59, 3.00, 3.00, and 4.90, respectively, while the largest effort levels that should be observed in equilibrium $(\bar{e})$ were 1.88, 2.11, 2.11 and 3.14, respectively. Thus in every treatment considerably more than $25 \%$ of all 
observed effort levels cannot be rationalized by equilibrium behavior. ${ }^{6}$ Subjects consistently chose higher tournament effort levels than equilibrium behavior would dictate-similar to the overbidding observed in all-pay auction experiments and consistent with the Dechenaux et al. conjecture concerning tournaments with little noise.

Considering average tournament effort choices obscures a trend of decreasing tournament effort over the course of a session observed in every treatment. For example, mean tournament effort in the first five periods of the LP treatment, 2.58, is significantly larger than the mean effort in the last five periods, $2.07(\mathrm{p}=0.000)$ —a trend common to winners and losers as Figure 2 illustrates. The average tournament effort among winners, however, is higher than 2.6 in all rulebased periods in the LP treatment, meaning that many winners are choosing effort levels outside the support of the equilibrium mixed strategy even after 40 periods. In the next subsection, we discuss a possible explanation for this overprovision of effort—namely that some individuals are "high effort" types who choose high effort levels regardless of the incentive scheme.

\section{V.B Production Stage Effort Provision}

The profit-maximizing effort in the production stage is two in all treatments. Table 3 summarizes the average efforts in the production stage. As in the tournament stage, subjects in all treatments on average choose effort levels that are significantly above the profit-maximizing level. Tournament outcomes are also related to subsequent effort provision: winners in all treatments choose significantly higher effort levels on average than losers. One explanation for the observed relationship between tournament outcomes and subsequent effort provision is that subjects fail to recognize that the profit-maximizing production stage effort choice is

\footnotetext{
${ }^{6}$ While studies have found that women's performance in competitive pay schemes suffers relative to a non-competitive environment (Gneezy et al. 2003) or that women avoid competition (Niederle \& Vesterlund 2007), women in our experiment choose significantly higher effort levels in the tournament stages than men in every treatment except the RM treatment (p-values less than 0.007 in each case).
} 
independent of tournament outcomes. We explored this possibility with the BL treatment in which there was no relationship between the tournament outcome and the production stage payoffs. Winners in the BL treatment also provide significantly more effort (2.43) than losers (2.28) - suggesting that strategic "confusion" cannot explain the relationship between tournament outcomes and subsequent effort provision. Alternatively, tournaments may serve as selection mechanisms: subjects who exert high effort levels in all environments are more likely to win tournaments and subsequently provide high effort levels in the production stage. Figure 2 provides evidence that this may be the case as winners' tournament stage and production stage efforts are higher on average than those of losers throughout the experiment.

Winning and losing, however, do not fully describe tournament outcomes; how one wins or loses may also be important. Table 3 further decomposes the production stage efforts for winners and losers by whether subjects won or lost in a rule-based or random outcome period. Subjects who lost in a random outcome period in the LP treatment chose significantly lower effort levels than losers who lost in rule-based periods (p-value 0.078). Losers in randomly decided tournaments in the other treatments also exert less effort than losers in rule-based tournaments-though the differences in these smaller samples are not statistically significant at conventional levels. The mean effort levels reported in table 3 understate the extent of this effort reduction if the selection effect described above influences tournament outcomes. To illustrate, suppose subjects are of two types: high effort individuals who choose high effort levels in all environments and low effort individuals who choose low effort levels in all environments. In the production stage if high effort types are more likely to win tournaments than low effort types, high effort types will be disproportionately represented among the winners, while low effort types will be disproportionately represented among the losers. This selection alone would lead to 
the differences between winners and losers in mean production stage effort levels that we observe. This selection would also influence the comparisons based on whether subjects won or lost in rule-based or randomly decided tournaments. In randomly decided tournaments, more "high effort" individuals would be losers than in rule-based tournaments, while more "low effort" individuals would be winners. This would tend to inflate the average production stage effort of losers in randomly decided tournaments relative to that of losers in rule-based tournaments while reducing the average production stage effort of winners in randomly decided tournaments relative to that of winners in rule-based tournaments.

The means reported in table 3 may also be affected by subjects' experiences over time. Subjects in all treatments reduce their production stage effort between the first five periods and the last five periods: from 2.95 to 2.18 in BL sessions, 3.06 to 2.21 in LP sessions, 3.06 to 2.18 in RM sessions, and 2.46 to 2.25 in the RPS sessions. Figure 3 depicts the average production stage effort levels in the LP treatments for tournament winners and losers by period. Both winners and losers reduce their average production stage effort over time; losers appear to converge on the profit-maximizing effort (2) after approximately twenty periods. Tournament winners consistently over-provide effort even after 40 periods.

To examine how tournament outcomes influence post-tournament behavior while accounting for changes in behavior over time and unobserved heterogeneity among subjects, table 4 presents regression estimates that address these issues in the LP treatment. In column 1, we regress a subject's production stage effort on a dummy variable equal to one if the subject won the tournament and period dummies. ${ }^{7}$ Consistent with the comparisons of means in table 3 , we find that tournament winners choose production stage effort levels that are an estimated 0.362

\footnotetext{
${ }^{7}$ We use eight dummy variables for blocks of five periods. The results are qualitatively and quantitatively similar if we use individual period dummies or a linear time trend.
} 
effort units higher than tournament losers—a large and statistically significant difference given that the average effort level in this treatment is 2.5 .

In column two, we add dummies indicating how a subject won or lost when the outcome was randomly determined. Specifically, these dummies indicate whether a subject would have won a rule-based tournament but lost the randomly decided tournament, would have won a rulebased tournament and won the randomly decided tournament, would have lost a rule-based tournament and lost the randomly decided tournament, and would have lost a rule-based tournament but won the randomly decided tournament. In some cases the random outcome reversed the rule-based outcome conditional on effort choices, while in other cases the random outcome was no different than the rule-based outcome would have been. Subjects knew whether they had won and whether the random resolution of the tournament affected the outcome.

Including indicators for how subjects won or lost in randomly determined periods, the estimated coefficient of the tournament winner dummy reflects differences between winners' and losers' production stage effort in rule-based periods. The estimated effect of being a tournament winner (0.342) is almost identical to that in column 1 . There is some evidence of effort reductions in random outcome periods: subjects who lost a randomly decided tournament and would have lost in a rule-based tournament reduce their production stage effort by a statistically significant 0.194 effort units. Otherwise, the estimates in column 2 suggest that subjects do not respond to random tournament outcomes in the production stage.

Unobserved heterogeneity among subjects in their tendencies to provide effort independent of the incentives to do so, however, would result in the estimates in column 2 overestimating the effect of losing in a random period when one would have won in a rule-based period and underestimating the effect of winning in a random period when one would have lost 
in a rule-based period. To address this issue, we jointly estimate models of the tournament stage effort and the production stage effort with subject fixed effects. We regress effort choices from both stages on a dummy for whether the observation comes from a tournament stage, a dummy for an observation from a production stage when the subject won the tournament, time dummies and their interaction with the tournament dummy, and subject fixed effects. Because the subject fixed effects are constrained to be the same in both the tournament stage effort model and the production stage effort model, we capture heterogeneity in the form of a tendency to choose high effort levels across different environments.

We resoundingly reject the hypothesis of no unobserved heterogeneity among subjects (F-test p-value $=0.000$ ). Figure 4 displays the difference between the mean fixed effects of winners and losers across periods in the LP treatment. The mean value of the subject fixed effects for winners is less than the mean value for losers just once in thirty rule based periods, while this difference is negative in three of ten random outcome periods and less than 0.18 in all but one random outcome period. In rule-based periods in the LP treatment, the distribution of fixed effects for winners is significantly different from that for losers (Kolmogorov-Smirnov $\mathrm{p}=0.000$ ), but the distributions are not significantly different in random outcome periods (Kolmogorov-Smirnov $\mathrm{p}=0.147$ ). These differences suggest that rule-based tournaments select subjects who choose on average high effort levels regardless of the incentive scheme to be "winners," a selection which is undone when tournaments are randomly decided.

Given this evidence of non-trivial heterogeneity among subjects in their inclinations toward providing effort regardless of incentives, we report in column 3 of table 4 the estimates when we jointly estimate the model of production stage effort in column 2 and the tournament model with common subject fixed effects. The estimates in column 3 indicate that being a 
tournament winner does not have a significant effect on production stage output in rule-based periods once we control for unobserved heterogeneity among the subjects. Using only withinsubject variation to identify the effect of winning a tournament on production stage effort, it is apparent that winners do not exert more effort in the production stage following a win because of their exuberance at winning or for any other reason. The estimated effects of being a winner on production stage effort in columns 1 and 2 stem entirely from the tendency of individuals who choose high effort levels in both environments to win tournaments. ${ }^{8}$

Given the relationship between the unobserved subject heterogeneity and the probability of winning a tournament, the estimated effects without controlling for unobserved subject heterogeneity of tournament outcomes on production stage output in random outcome periods will only be biased when the random outcome is different from the outcome that would have prevailed had the output rule been used to decide the tournament. Consistent with this expectation, we observe that winning by chance when one would have won under the output rule is associated with essentially no change in production stage effort while losing when one would have lost in a rule-based period is associated with a reduction in production stage effort of 0.158 effort units - both effects similar to what we observe when we do not account for selection in column 2. By contrast, controlling for unobserved heterogeneity among subjects leads to significantly different estimated effects from those in column 2 of tournament outcomes on production stage effort in random outcome periods when the random outcome is at odds with what would have prevailed in a rule-based period. Losing a randomly decided tournament when one would have won under the output rule is associated with an estimated reduction in the effort of 0.32 effort units $-12.8 \%$ of the average production stage effort. Curiously, winning a

\footnotetext{
${ }^{8}$ In results available from the authors, we test whether men and women respond differently to tournament losses as in Gill and Prowse (2012a). We do not find any significant gender differences.
} 
randomly decided tournament when one would have lost under the output rule is associated with a 0.30 effort unit increase in production stage effort—possibly reflecting subjects' exuberance at getting truly "lucky."

Gill and Prowse (2012a) also find that tournament outcomes influence subsequent effort choices, albeit in subsequent tournaments. The authors suggest that their results are consistent with a model of "just deserts" in which agents are trying to bring subsequent earnings in line with beliefs about what one deserves. Similar desert concerns cannot explain our findings. Random outcomes have an asymmetric effect on winners and losers in that they increase effort from only those winners who would otherwise have lost, but they decrease effort from losers irrespective of whether the randomness changed the outcome. If desert concerns were at work, one would expect undeserving winners and losers to reduce effort while the behavior of deserving winners and losers would not be influenced by the random outcomes; this is not what we observe. As such, we investigate alternative explanations for our findings in the next section.

\section{V.C Nature of Effort Reduction}

One of our behavioral hypotheses elaborated at the beginning of section IV is that “unlucky” losers harbor an animus towards those who benefit from their bad luck as Schaubroek and Lam’s (2004) findings suggest. In our experiment, subjects are identical ex ante, and their displeasure with the perceived capriciousness of random tournament outcomes might be aimed at the direct beneficiary of their bad luck - their partners in the tournament stage.

The RM treatment allows us to test this hypothesis by matching subjects with new partners between the tournament and production stages. If subjects reduce their effort to reduce the total payout to the subject who benefitted at their expense, then tournament outcomes should not be related to production stage effort in the RM treatment. Column 1 of table 5 reports the 
estimates from the jointly estimated tournament and production stage models with subject fixed effects for the RM treatment. The effects of tournament outcomes on production stage effort are similar to those in the LP treatments, and we fail to reject equality of the coefficients of the random outcome dummies with those from the LP treatment in column 3 of table 4 . The data do not support the hypothesis that a desire to reduce the payoff to the direct beneficiary of the randomness in one's own tournament motivates effort reductions in random outcome periods.

Another reality of workplaces is that work relationships do not necessarily end shortly after a tournament is decided. Workers often continue working together for long periods after promotions, and reactions to tournament outcomes may be short-lived. Cohen-Charash and Mueller (2007) find that episodic envy and perceived unfairness predicted interpersonal CWBs. ${ }^{9}$ In this sense, we hypothesize that CWBs may be a "hot state" reaction to perceived unfairness, and as workers "cool down" and weigh the potential consequences of CWBs such as being terminated they may engage in fewer CWBs. Similarly, if the increase in effort among "lucky" winners in random outcome periods results from their exuberance at their good fortune, this effort increase may decrease over time as their exuberance dissipates.

To test the hypothesis that effort responses to random outcomes are short-lived phenomena, subjects participated in four production stages after the tournament in the RPS treatment. In table 5 we report the estimated coefficients for a model of production stage effort when it is jointly estimated with the tournament stage model with subject fixed effects allowing the effects of random tournament outcomes to vary across production stages. We fail to reject the hypothesis that the random outcome dummy coefficients for the first production stage of the RPS treatment are equal to those in the LP treatment in table 4. Moreover, we fail to reject the

\footnotetext{
${ }^{9}$ The term "episodic" refers to situations in which an event or outcome sharpens feelings of unfairness and envy that might exist in a constant, low-grade state otherwise (Cohen-Charash \& Mueller 2007).
} 
null hypothesis that the estimated random outcome dummy coefficients in columns 3 through 6 are jointly equal to zero for each production stage after the first. Consistent with our hypothesis, effort responses to random outcomes appear to be short-lived such that tournament designers and managers who wish to mitigate potential effort reductions can focus on the immediate aftermath of the promotion decision.

Our final hypothesis is that some subjects reduce their effort when random outcomes offend their preference for meritocratic outcomes in the spirit of the "Protestant work ethic." Weber (1904) argued that in Protestant theology, hard work and frugality—and the wealth and social standing that followed—were signs that one was favored by Providence, and this belief about the value of hard work shaped preferences and promoted economic growth in Protestant countries. Severing the link between effort and outcomes is likely to offend this sensibility among those with a strong preference for meritocratic outcomes, which we measure with the Preference for Merit Principle Scale (PMP) in our questionnaire. A higher score on the PMP indicates that a subject feels more strongly that their rewards ought to be consistent with their effort choices; the complete scale can be found in the Appendix.

Although our hypothesis relates effort reductions to preferences for merit, PMP scores for subjects in the LP treatment are significantly correlated with their conscientiousness scores $(\rho=$ 0.341, $\mathrm{p}=0.008$ ). Moreover, industrial/organizational psychologists have found that the Big 5 personality traits (i.e., openness/intellect, agreeableness, extroversion, conscientiousness, and emotional stability) are related to how CWBs are expressed (Salgado 2002, Mount and Johnson 2006, Bolton et al. 2010). ${ }^{10}$ As such, we augment the specification in column 3 of table 4 for the

\footnotetext{
${ }^{10}$ Bolton et al. (2010) find that workers with high openness/intellect scores were more likely to engage in production deviance behaviors such as taking long breaks and leaving early. Salgado (2002) and Mount and Johnson (2006) both find that workers low in agreeableness are likely to engage in interpersonal
} 
LP treatment by introducing interactions between the random outcomes and PMP and each of the Big 5 personality traits in the production stage effort model in the specification reported in table 6 to examine more broadly whether reactions to random tournament outcomes are related to observable subject characteristics. The scores for the Big 5 traits and the PMP have been standardized such that an increase of one unit for each measure corresponds to a one standard deviation increase within our sample.

Consistent with our hypothesis, subjects with strong preferences for meritocratic outcomes react more strongly than other subjects to losing tournaments randomly—regardless of whether they would have won under the output rule—-by reducing their production stage effort. In a randomly decided tournament in which a subject loses, a one standard deviation increase in the PMP score is associated with an estimated 0.25 unit reduction in production stage effort when the subject would have lost under the output rule and a 0.32 unit reduction when the subject would have won under the output rule. When subjects win in randomly decided tournaments, however, their preferences for merit are unrelated to their production stage behavior, suggesting that subjects with strong preferences for merit only chafe at nonmeritocratic outcomes when these outcomes are unfavorable. ${ }^{11}$

We observe relationships between personality traits and reactions to random outcomes, but none which are consistent with prior studies relating CWBs to personality traits. More extroverted (“open” or "intellectually oriented”) subjects reduce (increase) their production stage effort more than other subjects when they would have won a tournament under the output rule but lost randomly. More conscientious subjects increase their effort when they win randomly tournaments that they would have won under the output rule, while more emotionally stable

CWBs such as harassment and verbal abuse, and that workers low in conscientiousness are more likely to engage in CWBs directed at the organization such as sabotage and reduced effort.

${ }^{11}$ We obtain almost identical estimates with respect to PMP omitting the personality interactions. 
subjects reduce their effort more than other subjects when they lose tournaments that they would have lost under the output rule. Our failure to find correlations between effort reductions following random outcomes and personality traits consistent with prior psychology research is perhaps unsurprising given that these studies themselves often reach different conclusions about how personality traits are related to CWBs.

\section{Conclusion}

Psychologists have documented that losing out on a promotion can lead to angry reactions by workers (Schwartzwald et al. 1992, Lemons \& Jones 2001, Schaubroeck \& Lam 2004, Bagdadli et al. 2006). Moreover, that tournaments are often used when effort is difficult to fully observe makes them fertile breeding grounds for feelings of unfairness - the primary driver of counterproductive workplace behaviors. Motivated by these findings and the fact that interactions among competitors rarely cease when a workplace tournament ends, we employ a laboratory experiment to examine whether tournament outcomes affect post-tournament effort.

We find that post-tournament effort choices are related to tournament outcomes in two ways. First, tournaments have the beneficial—if not surprising—feature that they tend to select for promotion subjects who choose higher effort levels regardless of the compensation scheme. Second, controlling for this individual heterogeneity in effort choices, subjects who lose in randomly decided tournaments significantly reduce their post-tournament effort relative to their effort following tournaments decided using an output rule regardless of whether the subject would have won under the output rule. In contrast to Bolton et al. (2005), this effort reduction occurs in spite of the fact that the random procedure occasionally determining the tournament outcome is unbiased in the sense that it does not favor one subject over another and that subjects are aware that this unbiased random procedure may determine the outcome in any tournament. 
To understand these reactions to tournament outcomes, we establish through additional treatments that the effort reductions were not aimed at the direct beneficiaries of the randomness and that the effort responses dissipate if subjects make several post-tournament effort choices. We show that effort reductions following randomly decided tournaments are highly correlated with subjects' preferences for merit: losers who prefer that outcomes be closely tied to their efforts reduce their effort more in periods in which the tournament outcome was decided randomly rather than by using the output rule than do other subjects.

Recent studies have examined how non-monetary preferences and motivations ranging from fear of being exploited by the firm (Barlting et al. 2012, Carpenter and Dolifka 2013), symbolic rewards in the workplace (Besley and Ghatak 2008, Kosfeld and Neckerman 2010), lack of trust by employers (Falk and Kosfeld 2006), and the legitimacy of authority within the firm (Tyler and Blader 2003, 2005) influence workers' behaviors. We examine a fundamental way in which non-monetary, behavioral considerations arise from competition between workers vying for a promotion: people do not like losing. In particular, people do not like losing when they perceive the outcome to be unfair or capricious, and this sensibility can influence their subsequent behavior. Our findings suggest that employees' decisions after a competition are a function of the competitive outcomes and interactions between these outcomes, their perception of the process determining these outcomes, and their personalities and preferences. Our findings indicate that anyone interested in designing effective incentive schemes when effort is not fully contractible should take a long-run view and consider how such schemes involving competition influence behavior once the dust settles and the competition is finished. Moreover, firms should take pains to ensure that competitions are perceived as fairly decided lest their disgruntled employees engage in counterproductive behaviors. 


\section{References}

Acquino, K., Lewis, M. \& Bradfield, M. (1999) “Justice constructs, negative affectivity, and employee deviance: A proposed model and empirical test,” Journal of Organizational Behavior, 20, pp.1073 - 1091

Altmann, S., Falk, A. \& Wibral, M. (2012) "Promotions and Incentives: The Case of Multistage Elimination Tournaments,” Journal of Labor Economics, 30, pp.149 - 174

Bagdadli, S., Roberson, Q. \& Paoletti, F. (2006) "The Mediating Role of Procedural Justice in Responses to Promotion Decisions,” Journal of Business and Psychology, 21 (1), pp. 83102

Bartling, B., Fehr, E. \& Schmidt, K. (2012) "Use and Abuse of Authority: A Behavioral Foundation of the Employment Relation,” University of Zurich Working Paper No. 98

Bennett, R. \& Robinson, S. (2000) “Devleopment of a measure of workplace deviance,” Journal of Applied Psychology, 85, pp. 349-360

Besley, T. \& Ghatak, M. (2008) “Status Incentives,” American Economic Review, 98 (2), pp. 206-211

Bolton, L., Becker, L. \& Barber, L. (2010) "Big Five trait predictors of differential counterproductive work behavior dimensions,” Personality and Individual Differences, 49, pp. 537-541

Bolton, G., Brandts, J. \& Ockenfels, A. (2005) "Fair Procedures: Evidence from Games Involving Lotteries,” The Economic Journal, 115 (506), pp. 1054-1076

Bolton, G. \& Ockenfels, A. (2000) “ERC: A Theory of Equity, Reciprocity, and Competition,” American Economic Review, 90 (1), pp. 166-193

Bull, C., Schotter, A. \& Weigelt, A. (1987) “Tournaments and Piece Rates: an Experimental Study,” Journal of Political Economy, 95, pp. 1-33

Carpenter, J., Matthews, P. \& Schirm, J. (2010) “Tournaments and Office Politics: Evidence from A Real Effort Experiment,” American Economic Review, 100, pp. 504-517

Carpenter, J. \& Dolifka, D. (2013) “Exploitation aversion: When financial incentives fail to motivate agents,” IZA Discussion Paper No. 7499

Charness, G. \& Rabin, M. (2002) “Understanding social preferences with simple tests," Quarterly Journal of Economics, 117, pp. 817-869

Che, Y.K. \& Gale, I. (2000) "Difference-Form Contests and the Robustness of All-Pay Auctions,” Games and Economic Behavior, 30, pp. 22-43 
Cohen-Charash, Y. \& Mueller, J. (2007) "Does Perceived Unfairness Exacerbate or Mitigate Interpersonal Counterproductive Work Behaviors Related to Envy?” Journal of Applied Psychology, 92 (3), pp. 666-680

Davey, L., Bobocel, D., Hing, L. \& Zanna, M. (1999) "Preference for the Merit Principle Scale: An Individual Difference Measure of Distributive Justice Preferences," Social Justice Research, 12 (3), pp. 223-240

Dechenaux, E., Kovenock, D. \& Sheremeta, R. (2012) "A survey of experimental research on contests, all-pay auctions and tournaments," Discussion Papers, Research Professorship \& Project "The Future of Fiscal Federalism" SP II 2012-109, Social Science Research Center Berlin (WZB)

Dufwenberg, M. \& Kirchsteiger, G. (2004) “A theory of sequential reciprocity,” Games and Economic Behavior, 47 (2), pp. 268-298

Dunlop, P. \& Lee, K. (2004) "Workplace deviance, organizational citizenship behavior, and work unit performance: The bad apples do spoil the whole barrel," Journal of Organizational Behavior, 25 (1), pp. 67-80

Falk, A., Fehr, E. \& Fischbacher, U. (2003) “On the nature of fair behavior,” Economic Inquiry, 41, pp. 20-26

Falk, A. \& Kosfeld, M. (2006) “The hidden cost of control,” American Economic Review, 96 (5), pp. 1611-1630

Fehr, E. \& Schmidt, K. (1999) “A Theory of Fairness, Competition, and Cooperation,” Quarterly Journal of Economics, 114 (3), pp. 817-868

Fischbacher, U. (2007) "zTree: Zurich Toolbox for Ready-Made Economic Experiments," Experimental Economics, 10 (2), pp. 171-178

Flaherty, S. \& Moss, S. (2007) "The impact of personality and team context on the relationship between workplace injustice and counterproductive work behavior," Journal of Applied Social Psychology, 37 (11), pp. 2549-2575

Fox, S. \& Spector, P. (2004) Counterproductive Work Behavior: Investigations of Actors and Targets. Washington, DC: APA Press

Gill, D. \& Prowse, V. (2012a) "Gender Differences and Dynamics in Competition: The Role of Luck," Oxford Department of Economics Discussion Paper 564

Gill, D. \& Prowse, V. (2012b) "A Structural Analysis of Disappointment Aversion in a Real Effort Competition,” American Economic Review, 102(1), pp. 469-503 
Gill, D. \& Stone, R. (2010) "Fairness and desert in tournaments," Games and Economic Behavior, 69 (2), pp. 346-364

Gneezy, U., Niederle, M. \& Rustichini, A. (2003) "Performance in Competitive Environments: Gender Differences,” Quarterly Journal of Economics, 118 (3), pp. 1049-1074

Goldberg, L. (1992) “The development of markers for the Big-Five factor structure,” Psychological Assessment, 4, pp. 26-42

Grund, C. \& Sliwka, D. (2005) "Envy and Compassion in Tournaments," Journal of Economics \& Management Strategy, 14 (1), pp. 187-207

Harbring, C. \& Irlenbusch, B. (2011) "Sabotage in Tournaments: Evidence from a Laboratory Experiment,” Management Science, 57, 611-627

Holt, C. \& Laury, S. (2002) "Risk Aversion and Incentive Effects," American Economic Review, 92 (5), pp. 1644-1655

Jones, D. (2009) "Getting even with one's supervisor and one's organization: relationships among types of injustice, desires for revenge, and counterproductive work behaviors," Journal of Organizational Behavior, 30 (4), pp. 525-542

Kosfeld, M. \& Neckerman, S. (2010) "Getting more work for nothing? Symbolic awards and worker performance,” IZA Working Paper No. 5040

Kräkel, M. (2008) “Emotions in tournaments," Journal of Economic Behavior and Organization, 67, pp. 204-214

Lazear, E. \& Rosen, S. (1981) "Rank-Order Tournaments as Optimum Labor Contracts," Journal of Political Economy, 89 (5), pp. 841-864

Lemons, M. \& Jones, C. (2001) "Procedural Justice in Promotion Decisions: Using Perceptions of Fairness to Build Employee Commitment,” Journal of Managerial Psychology, 16 (4), pp. 268-281

Martinko, M., Gundlach, M. \& Douglas, S. (2002) "Toward an Integrative Theory of Counterproductive Workplace Behavior: A Causal Reasoning Perspective,” International Journal of Selection and Assessment, 10 (1), pp. 36-50

Markus, B. \& Shuler, H. (2004) "Antecedents of counterproductive behavior at work: A general perspective,” Journal of Applied Psychology, 89 (4), pp. 647-660

Mount, M., Ilies, R. \& Johnson, E. (2006) "Relationship of personality traits and counterproductive work behaviors: The mediating effects of job satisfaction,” Personnel Psychology, 59, pp. 591-622 
Nalbantian, H. \& Schotter, A. (1997) "Productivity under Group Incentives: An Experimental Study,” American Economic Review, 87, pp. 314-341

Nalebuff, B. \& Stiglitz, J. (1983) "Prizes and Incentives: Towards a General Theory of Compensation and Competition,” The Bell Journal of Economics, 14 (1), pp. 21-43

Niederle, M. \& Vesterlund, L. (2007) "Do Women Shy Away from Competition? Do Men Compete Too Much?” Quarterly Journal of Economics, 122 (3), pp. 1067-1101

Nieken, P. (2010) "On the Choice of Risk and Effort in Tournaments: Experimental Evidence," Journal of Economics and Management Strategy, 19 (3), pp. 811-840

Rabin, M. (1993) “Incorporating fairness into game theory and economics,” American Economic Review, 83, pp. 1281-1302

Rotter, J. (1966) “Generalized Expectancies for Internal Versus External Control of Reinforcement,” Psychological Monographs General and Applied, 80 (1, Whole No. 609)

Salgado, J. (2002) “The Big Five personality dimensions and counterproductive behaviors," International Journal of Selection and Assessment, 10, pp. 117-125

Schaubroeck, J. \& Lam, S. (2004) “Comparing Lots Before and After: Promotion Rejectees’ Invidious Reactions to Promotees,” Organizational Behavior and Human Decision Processes, 94 (2004), pp. 33-47

Scheier, M., Carver, C. \& Bridges, M. (1994) “Distinguishing optimism from neuroticism (and trait anxiety, self-mastery, and self-esteem): A re-evaluation of the Life Orientation Test.” Journal of Personality and Social Psychology, 67, pp. 1063-1078

Schotter, A. \& Weigelt, K. (1992) “Asymmetric Tournaments, Equal Opportunity Laws, and Affirmative Action: Some Experimental Results,” Quarterly Journal of Economics, 107, pp. 511-539

Schwarzwald, J., Koslowsky, M. \& Shalit, B. (1992) “A Field Study of Employees’ Attitudes and Behaviors After Promotion Decisions,” Journal of Applied Psychology, 77 (4), pp. 511-514

Sheremeta, R. \& Wu, S. (2011) “Optimal Tournament Design and Incentive Response: An Experimental Investigation of Canonical Tournament Theory,” Working Paper.

Skarlicki, D. \& Folger, R. (1997) "Retaliation in the workplace: The roles of distributive, procedural, and interactional justice,” Journal of Applied Psychology, 82, pp. 434-443 
Skarlicki, D., Folger, R., \& Tesluk, P. (1999) "Personality as a moderator in the relationship between fairness and retaliation,” Academy of Management Journal, 42, pp. 100-108

Tong, K. \& Leung, K. (2002) "Tournament as a Motivational Strategy: Extension to Dynamic Situations with Uncertain Duration,” Journal of Economic Psychology, 23, pp. 399-420

Tyler, T. \& Blader, S. (2003) "Procedural justice, social identity, and cooperative behavior," Personality and Social Psychology Review, 7, pp. 349-361

Tyler, T. \& Blader, S. (2005) "Can businesses effectively regulate employee conduct? The antecedents of rule following in work settings," Academy of Management Journal, 48 (6), pp. 1143-1158

Weber, M. (1904) The Protestant Ethic and the Spirit of Capitalism, Routledge: New York 
Figure 1: Kernel Density Plots of Tournament Stage Effort Choices

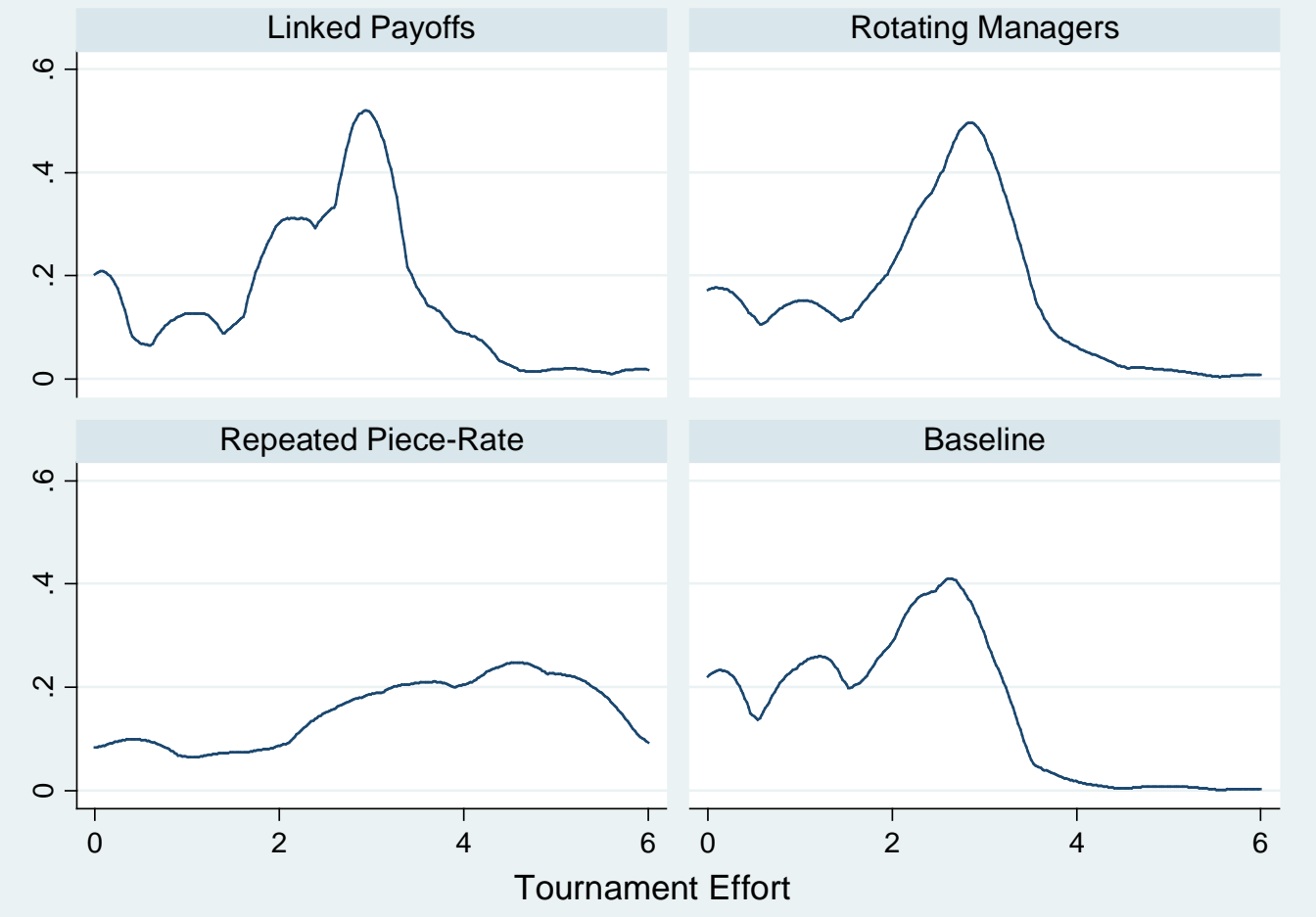

Note: The plots are generated using the Epanechnikov kernel function. There are 2400 observations for the linked payoff treatment, 1564 observations for the rotating manager treatment, 852 observations for the repeated piece rate treatment, and 1200 observations for the baseline treatment. 
Figure 2: Average Effort Over Time in the Linked Payoff Treatment

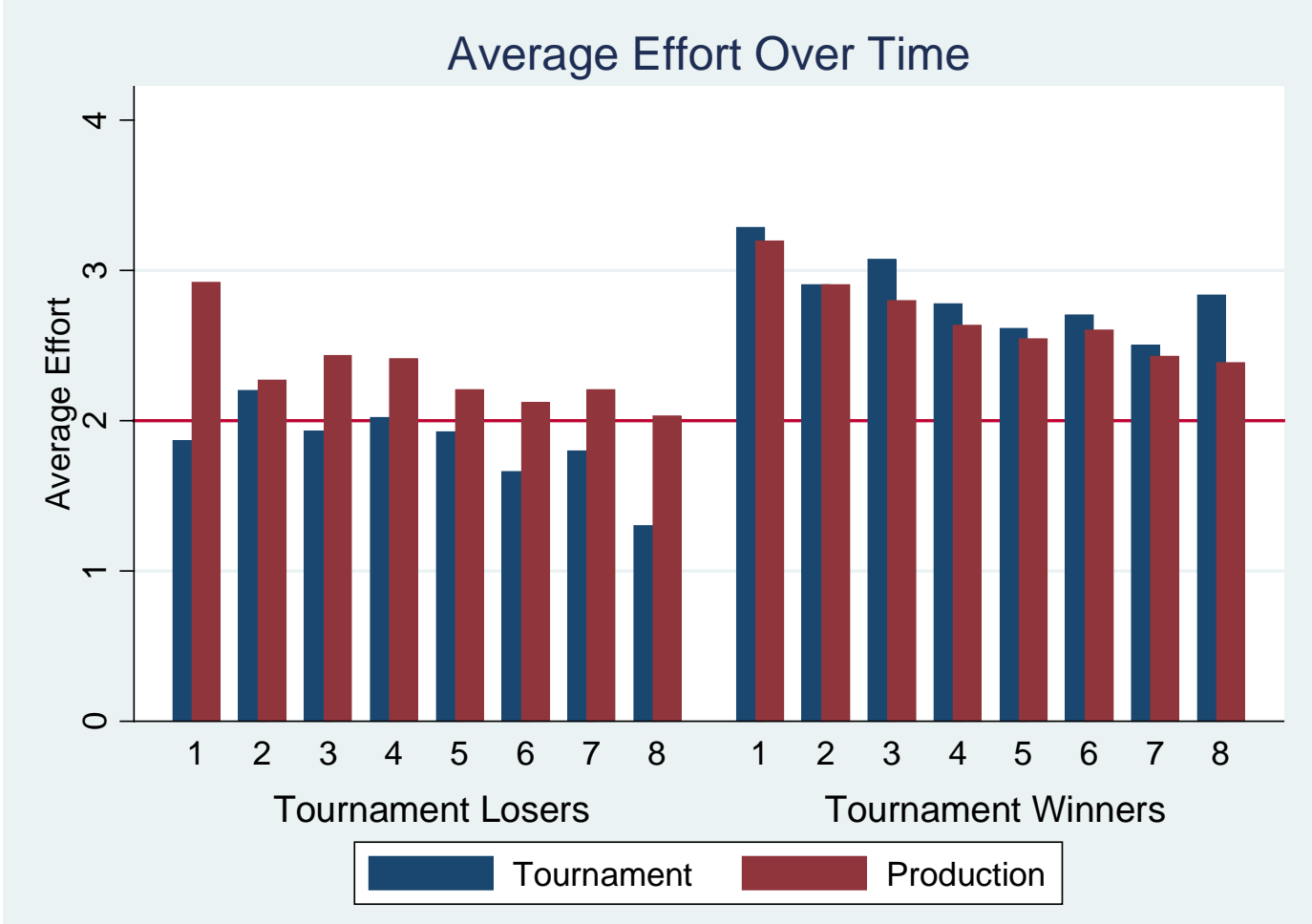

Note: The x-axis breaks up periods into groups of five. The first bar represents the average effort choice in periods $1-5$, the second average effort choice in periods $6-10$, and so on. The vertical line at $e=2$ represents the profit-maximizing effort level in the production stage. 
Figure 3: Average Production Stage Effort Over Time In Rule-Based Periods in the Linked Payoff Treatment

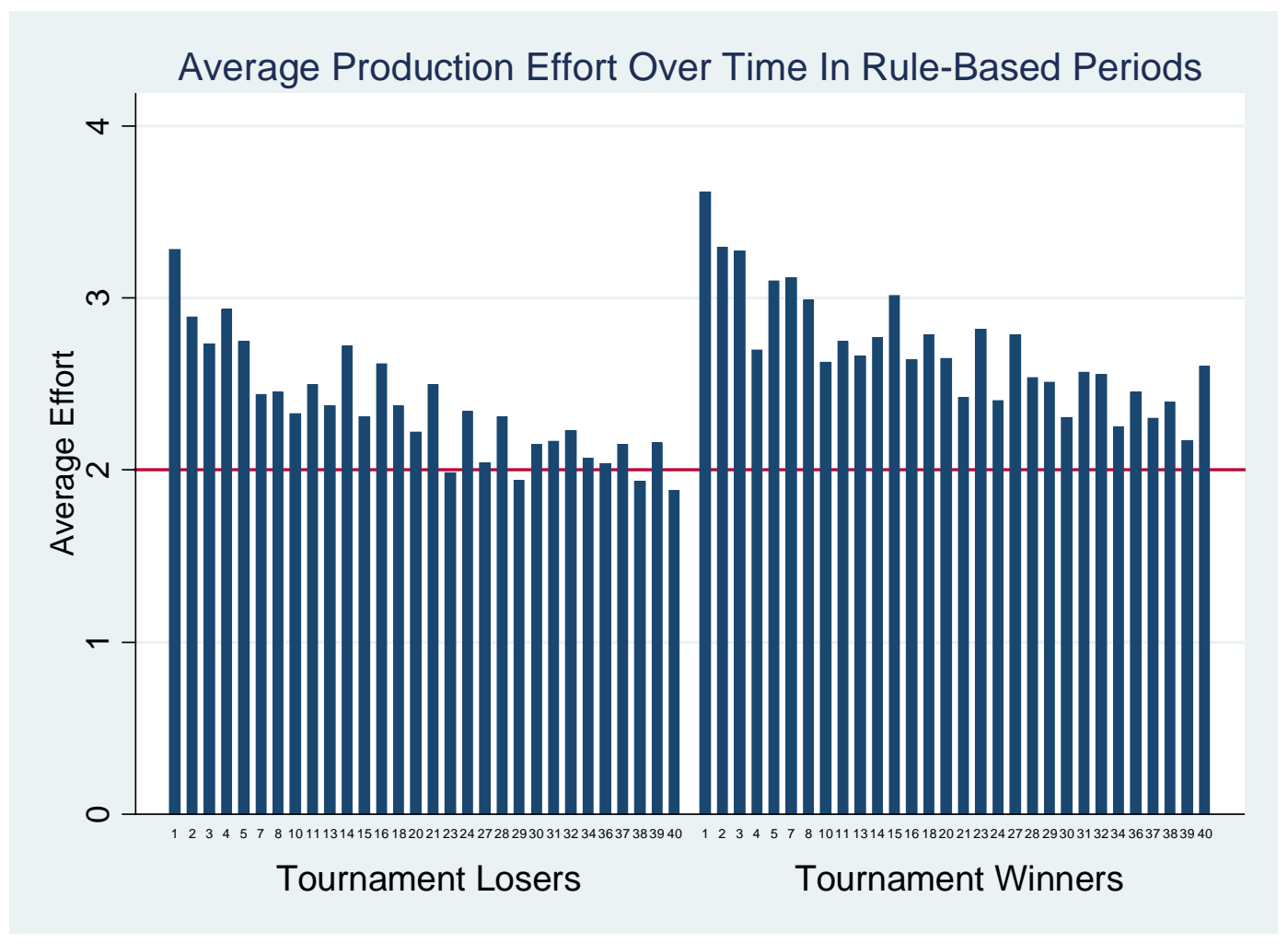

Note: The vertical line at $e=2$ represents the profit-maximizing effort in the production stage. 
Figure 4: Difference between the Means of Fixed Effects for Tournament Winners and Tournament Losers Across Periods in the Linked Payoff Treatment

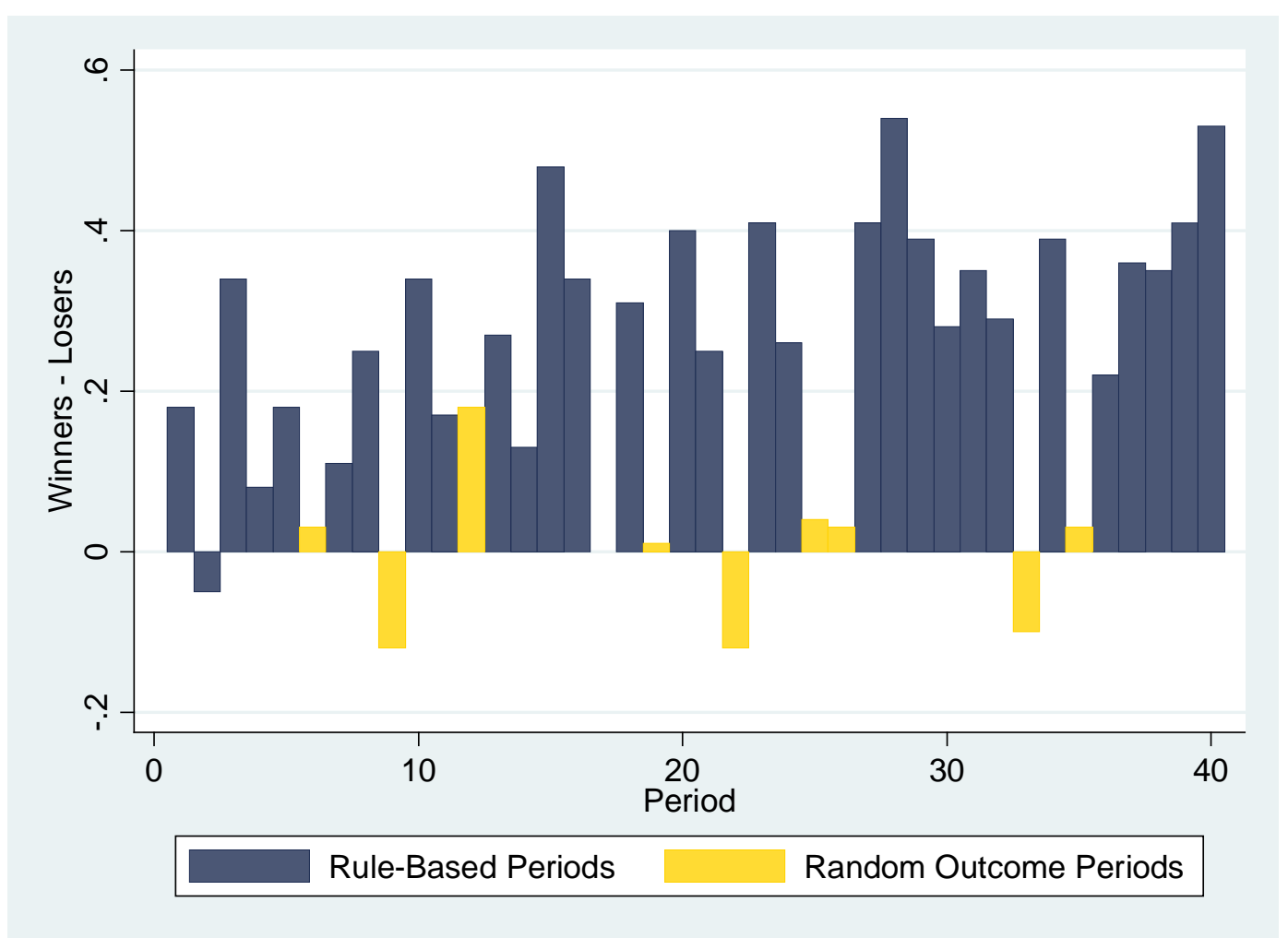

Note: The subject fixed effects were estimated by regressing subjects' effort choices in both stages on an indicator for whether the effort observation comes from a tournament stage, an indicator of whether a production stage observation comes from a subject who won the tournament, time dummies (in blocks of 5 periods), and interactions of the time dummies with the tournament indicator. 
Table 1: Summary of Experimental Sessions

\begin{tabular}{|c|c|c|c|c|c|}
\hline \multirow[b]{2}{*}{ Session type } & \multirow[b]{2}{*}{$\begin{array}{l}\text { Number of } \\
\text { Sessions }\end{array}$} & \multirow[b]{2}{*}{$\begin{array}{l}\text { Number of } \\
\text { subjects }\end{array}$} & \multicolumn{3}{|c|}{ Subject-tournament observations } \\
\hline & & & $\begin{array}{l}\text { Rule-based } \\
\text { outcome }\end{array}$ & $\begin{array}{l}\text { Random } \\
\text { outcome }\end{array}$ & $\begin{array}{l}\text { Average } \\
\text { earnings }\end{array}$ \\
\hline Baseline & 2 & 30 & 1200 & 0 & $\$ 20.47$ \\
\hline Linked Payoffs & 7 & 60 & 1800 & 600 & $\$ 24.00$ \\
\hline Rotating Managers & 4 & 44 & 1152 & 412 & $\$ 23.56$ \\
\hline Repeated Production Stage & 4 & 34 & 640 & 212 & $\$ 27.36$ \\
\hline Total & 15 & 148 & 4792 & 1224 & $\$ 23.72$ \\
\hline
\end{tabular}

Note: Sessions were conducted at Simon Fraser University. Subjects participated in only one session. For all treatments except the Repeated Production Stage treatment, the number of subject-production stage observations will be equal to the number of subject-tournament observations; for the Repeated Production Stage treatment, there are four subject-production stage observations for each subject-tournament observation. 
Table 2: Average Tournament Effort by Treatment and Tournament Outcome

\begin{tabular}{cllll}
\hline & Baseline & Linked Payoffs & $\begin{array}{l}\text { Rotating } \\
\text { Manager }\end{array}$ & $\begin{array}{l}\text { Repeated } \\
\text { Production Stage }\end{array}$ \\
\hline Overall & 1.79 & 2.34 & 2.21 & 3.47 \\
& $(1.10)$ & $(1.23)$ & $(1.21)$ & $(1.72)$ \\
Tournament Winners & {$[0.000]$} & {$[0.000]$} & {$[0.000]$} & {$[0.000]$} \\
& 2.41 & 2.84 & 2.68 & 4.17 \\
Rule-Based Outcomes & $(0.87)$ & $(1.06)$ & $(1.06)$ & $(1.33)$ \\
& {$[0.000]$} & {$[0.000]$} & {$[0.000]$} & {$[0.000]$} \\
Random Outcomes & & 3.02 & 2.88 & 4.31 \\
& & $(0.96)$ & $(0.93)$ & $(1.16)$ \\
Tournament Losers & & {$[0.000]$} & {$[0.000]$} & {$[0.000]$} \\
& & 2.27 & 2.13 & 3.77 \\
Rule-Based Outcomes & $(1.16)$ & $(1.18)$ & $(1.71)$ \\
& & {$[0.000]$} & {$[0.000]$} & {$[0.000]$} \\
Random Outcomes & 1.18 & 1.84 & 1.74 & 2.77 \\
& $(0.95)$ & $(1.18)$ & $(1.17)$ & $(1.77)$ \\
& & {$[0.000]$} & {$[0.000]$} & {$[0.000]$} \\
& & 1.66 & 1.55 & 2.51 \\
& & $(1.10)$ & $(1.10)$ & $(1.67)$ \\
& & {$[0.000]$} & {$[0.010]$} & {$[0.000]$} \\
& & 2.37 & 2.28 & 3.56 \\
& & $(1.24)$ & $(1.19)$ & $(1.85)$ \\
& & {$[0.000]$} & {$[0.000]$} & {$[0.000]$} \\
\hline \hline
\end{tabular}

Note: Standard deviations in parentheses. P-values in brackets are for tests of the null hypothesis that the average tournament stage effort in each treatment is equal to the expected effort of the equilibrium mixed strategy. 
Table 3: Average Production Stage Effort by Treatment and Tournament Outcome

\begin{tabular}{|c|c|c|c|c|}
\hline & Baseline & Linked Payoffs & $\begin{array}{l}\text { Rotating } \\
\text { Manager }\end{array}$ & $\begin{array}{l}\text { Repeated } \\
\text { Production Stage }\end{array}$ \\
\hline \multirow[t]{3}{*}{ Overall } & $2.35^{\mathrm{a}}$ & $2.50^{\mathrm{b}}$ & $2.45^{\mathrm{c}}$ & $2.26^{\mathrm{d}}$ \\
\hline & $(0.03)$ & $(0.03)$ & $(0.03)$ & $(0.03)$ \\
\hline & {$[0.000]$} & {$[0.000]$} & {$[0.000]$} & {$[0.000]$} \\
\hline \multirow[t]{3}{*}{ Tournament Winners } & $2.43_{\mathrm{e}}$ & $2.69^{\mathrm{f}}$ & $2.53^{\mathrm{g}}$ & $2.31^{\mathrm{h}}$ \\
\hline & $(0.04)$ & $(0.03)$ & $(0.04)$ & $(0.04)$ \\
\hline & {$[0.000]$} & {$[0.000]$} & {$[0.000]$} & {$[0.000]$} \\
\hline \multirow[t]{3}{*}{ Rule-Based Outcomes } & & $2.70^{\mathrm{i}}$ & $2.57^{\mathrm{j}}$ & $2.32^{k}$ \\
\hline & & $(0.04)$ & $(0.05)$ & $(0.05)$ \\
\hline & & {$[0.000]$} & {$[0.000]$} & {$[0.000]$} \\
\hline \multirow[t]{3}{*}{ Random Outcomes } & & $2.64^{1}$ & $2.43^{\mathrm{m}}$ & $2.27^{\mathrm{n}}$ \\
\hline & & $(0.07)$ & $(0.08)$ & $(0.07)$ \\
\hline & & {$[0.000]$} & [0.000] & {$[0.000]$} \\
\hline \multirow[t]{3}{*}{ Tournament Losers } & $2.28^{\circ}$ & $2.32^{\mathrm{p}}$ & $2.37^{\mathrm{q}}$ & $2.22^{\mathrm{r}}$ \\
\hline & $(0.04)$ & $(0.04)$ & $(0.04)$ & $(0.05)$ \\
\hline & {$[0.000]$} & {$[0.000]$} & {$[0.000]$} & {$[0.000]$} \\
\hline \multirow{3}{*}{ Rule-Based Outcomes } & & $2.36^{\mathrm{s}}$ & $2.40^{\mathrm{t}}$ & $2.25^{\mathrm{u}}$ \\
\hline & & $(0.04)$ & $(0.05)$ & $(0.06)$ \\
\hline & & {$[0.000]$} & {$[0.000]$} & {$[0.000]$} \\
\hline \multirow{12}{*}{ Random Outcomes } & & $2.22^{\mathrm{v}}$ & $2.27^{\mathrm{w}}$ & $2.13^{y}$ \\
\hline & & $(0.07)$ & $(0.08)$ & $(0.09)$ \\
\hline & & {$[0.002]$} & [0.001] & {$[0.148]$} \\
\hline & \multicolumn{4}{|c|}{ p-values of comparisons of means } \\
\hline & & a-b [0.0002] & a-c [0.0238] & a-d [0.0415] \\
\hline & & e-f [0.0000] & e-g [0.0778] & e-h [0.0356] \\
\hline & e-o [0.0069] & i-l $[0.4351]$ & $\mathrm{j}-\mathrm{m}[0.1571]$ & k-n [0.6121] \\
\hline & & f-p [0.0000] & g-q [0.0075] & h-r [0.2260] \\
\hline & & o-p [0.4333] & o-q [0.1418] & o-r [0.3864] \\
\hline & & s-v [0.0779] & $\mathrm{t}-\mathrm{w}[0.1672]$ & u-y [0.3334] \\
\hline & & o-s [0.1785] & o-t [0.0557] & o-u [0.7094] \\
\hline & & $\mathrm{o}-\mathrm{v}[0.3936]$ & $\mathrm{o}-\mathrm{w}[0.8762]$ & o-y [0.1536] \\
\hline
\end{tabular}

Note: Standard deviations in parentheses. The profit maximizing effort in the production stage is 2 in all treatments. For the repeated piece rate treatment, the value reported is for the first production stage after the tournament. P-values in brackets in the upper panel are for tests of the null hypothesis that the average effort is equal to 2 . The hypotheses tested in the lower panel are that the two means in question are equal. 
Table 4: Models of production stage effort in the Linked Payoff Treatment

\begin{tabular}{llll}
\hline & $(1)$ & $(2)$ & $(3)$ \\
\hline 1 if $1^{\text {st }}$ stage winner & $0.362^{* * *}$ & $0.342^{* * *}$ & 0.043 \\
1 if random loser (rule loser) & $(0.078)$ & $(0.082)$ & $(0.084)$ \\
& & $-0.194^{* *}$ & $-0.158^{*}$ \\
& & $(0.085)$ & $(0.081)$ \\
1 if random loser (rule winner) & & 0.020 & $-0.321^{* *}$ \\
& & $(0.134)$ & $(0.135)$ \\
1 if random winner (rule loser) & & -0.015 & $0.296^{* * *}$ \\
& & $(0.106)$ & $(0.092)$ \\
1 if random winner (rule winner) & & 0.002 & -0.005 \\
& & $(0.070)$ & $(0.059)$ \\
1 if observation from tournament stage & & & $-0.460^{* * *}$ \\
& & & $(0.148)$ \\
Period dummies & & & \\
Jointly estimated with model of tournament effort and fixed effects & Yo & Yes & Yes \\
$\mathrm{R}^{2}$ & 0.062 & 0.063 & Yes \\
\hline \hline
\end{tabular}

Note: Robust standard errors clustered at the subject level in parentheses. The period dummies are dummies equal to one if the observation comes from a block of 5 periods. That is, the first dummy is equal to one if the observation comes from periods $1-5$, the second dummy is equal to one if the observation comes from periods $6-10$, and so on. The dependent variable in columns (1) and (2) is the production stage effort choice. The dependent variable in column (3) is the effort choice from either stage. In column 3, the specification includes eight period block dummies interacted with the stage (tournament or production).

*** — significant at $1 \%$ level, ** — significant at $5 \%$ level, * — significant at $10 \%$ level 
Table 5: Models of Production Stage Effort in Rotating Manager and Repeated Production Stage Treatments

\begin{tabular}{|c|c|c|c|c|c|}
\hline \multirow[b]{3}{*}{ Variable } & \multicolumn{5}{|c|}{ Treatment } \\
\hline & \multirow[t]{2}{*}{ Rotating Manager } & \multicolumn{4}{|c|}{ Repeated Production Stage } \\
\hline & & $\begin{array}{l}\text { First } \\
\text { Production } \\
\text { Stage }\end{array}$ & $\begin{array}{l}\text { Second } \\
\text { Production } \\
\text { Stage }\end{array}$ & $\begin{array}{l}\text { Third } \\
\text { Production } \\
\text { Stage }\end{array}$ & $\begin{array}{l}\text { Fourth } \\
\text { Production } \\
\text { Stage }\end{array}$ \\
\hline 1 if $1^{\text {st }}$ stage winner & $\begin{array}{l}-0.063 \\
(0.112)\end{array}$ & $\begin{array}{l}-0.118 \\
(0.147)\end{array}$ & $\begin{array}{l}0.157^{*} \\
(0.088)\end{array}$ & $\begin{array}{l}0.099 \\
(0.111)\end{array}$ & $\begin{array}{l}0.021 \\
(0.027)\end{array}$ \\
\hline 1 if random loser (rule loser) & $\begin{array}{l}-0.106 \\
(0.125)\end{array}$ & $\begin{array}{l}-0.090 \\
(0.138)\end{array}$ & $\begin{array}{l}0.285 \\
(0.173)\end{array}$ & $\begin{array}{l}0.104 \\
(0.173)\end{array}$ & $\begin{array}{l}-0.010 \\
(0.033)\end{array}$ \\
\hline 1 if random loser (rule winner) & $\begin{array}{l}-0.348^{* *} \\
(0.140)\end{array}$ & $\begin{array}{l}-0.374 * * \\
(0.150)\end{array}$ & $\begin{array}{l}0.275 \\
(0.167)\end{array}$ & $\begin{array}{l}0.153 \\
(0.158)\end{array}$ & $\begin{array}{l}0.036 \\
(0.037)\end{array}$ \\
\hline 1 if random winner (rule loser) & $\begin{array}{l}0.277 \\
(0.188)\end{array}$ & $\begin{array}{l}0.275 * * \\
(0.127)\end{array}$ & $\begin{array}{l}-0.050 \\
(0.111)\end{array}$ & $\begin{array}{l}0.031 \\
(0.198)\end{array}$ & $\begin{array}{l}0.039 \\
(0.042)\end{array}$ \\
\hline 1 if random winner (rule winner) & $\begin{array}{l}-0.036 \\
(0.089)\end{array}$ & $\begin{array}{l}-0.075 \\
(0.069)\end{array}$ & $\begin{array}{l}-0.040 \\
(0.078)\end{array}$ & $\begin{array}{l}-0.132 \\
(0.094)\end{array}$ & $\begin{array}{l}-0.029 \\
(0.024)\end{array}$ \\
\hline 1 if observation from tournament stage & $\begin{array}{l}-0.363^{*} \\
(0.199)\end{array}$ & $\begin{array}{l}0.509 * * \\
(0.208)\end{array}$ & & & \\
\hline $\begin{array}{l}1 \text { if observation from production stage } \\
\text { after first production stage }\end{array}$ & & & $\begin{array}{l}-0.171^{* *} \\
(0.077)\end{array}$ & $\begin{array}{l}-0.101 \\
(0.089)\end{array}$ & $\begin{array}{l}-0.031 \\
(0.019)\end{array}$ \\
\hline $\begin{array}{l}\text { p-value of hypothesis test that } \\
\text { coefficients are jointly equal to } 0\end{array}$ & & & 0.323 & 0.607 & 0.456 \\
\hline $\mathrm{R}^{2}$ & 0.274 & 0.322 & & & \\
\hline
\end{tabular}

Note: Standard errors in parentheses. Both specifications jointly estimate models of the tournament and production stage effort choices with common subject fixed effects. The dependent variable is the effort choice in either the tournament or production stage. Both models include eight period block dummies.

*** — significant at $1 \%$ level, ** — significant at $5 \%$ level, * — significant at $10 \%$ level 
Table 6: Models of Production Stage Effort including Personality Measures in Linked Payoff Treatment

\begin{tabular}{|c|c|c|c|c|c|c|c|}
\hline & \multicolumn{7}{|c|}{ Random Outcome Dummies Interacted with } \\
\hline Variable & & Big 1 & Big 2 & Big 3 & Big 4 & Big 5 & PMP \\
\hline \multirow[t]{2}{*}{1 if $1^{\text {st }}$ stage winner } & 0.058 & -0.089 & 0.008 & 0.148 & -0.137 & 0.029 & -0.121 \\
\hline & $(0.084)$ & $(0.080)$ & $(0.114)$ & (0.098) & $(0.141)$ & $(0.088)$ & $(0.097)$ \\
\hline \multirow[t]{2}{*}{1 if random loser (rule loser) } & $-0.252^{* * *}$ & -0.153 & 0.026 & -0.084 & $-0.368 * * *$ & 0.036 & $-0.245^{* *}$ \\
\hline & $(0.092)$ & $(0.122)$ & $(0.097)$ & $(0.131)$ & $(0.135)$ & $(0.087)$ & $(0.102)$ \\
\hline \multirow[t]{2}{*}{1 if random loser (rule winner) } & -0.196 & $-0.285 * *$ & 0.174 & 0.074 & 0.097 & $0.439 * *$ & $-0.315^{* *}$ \\
\hline & $(0.141)$ & $(0.115)$ & $(0.160)$ & $(0.137)$ & $(0.194)$ & $(0.169)$ & $(0.136)$ \\
\hline \multirow[t]{2}{*}{1 if random winner (rule loser) } & $0.275^{* *}$ & -0.124 & 0.086 & -0.033 & 0.020 & 0.168 & 0.047 \\
\hline & $(0.103)$ & $(0.106)$ & $(0.130)$ & (0.119) & $(0.126)$ & $(0.146)$ & $(0.104)$ \\
\hline \multirow{2}{*}{$\begin{array}{l}1 \text { if random winner (rule } \\
\text { winner) }\end{array}$} & 0.012 & 0.096 & 0.049 & 0.096 & 0.059 & 0.009 & -0.087 \\
\hline & $(0.052)$ & $(0.076)$ & $(0.079)$ & $(0.087)$ & $(0.086)$ & $(0.071)$ & $(0.084)$ \\
\hline $\begin{array}{l}1 \text { if observation from } \\
\text { tournament stage }\end{array}$ & $\begin{array}{l}-0.466 * * * \\
(0.149)\end{array}$ & & & & & & \\
\hline $\mathrm{R}^{2}$ & 0.240 & & & & & & \\
\hline
\end{tabular}

Note: Standard errors in parentheses. The specification jointly estimate models of the tournament and production stage effort choices with common subject fixed effects. The dependent variable is the effort choice in either the tournament or production stage. The specification includes eight period block dummies interacted with the stage (tournament or production). Big 1 is Extroversion, Big 2 is Agreeableness, Big 3 is Conscientiousness, Big 4 is Emotional Stability, Big 5 is Openness/Intellect, and PMP is the Preference for Merit. All personality measures and the PMP are standardized within the sample to have mean zero and standard deviation one. $* * *$ — significant at $1 \%$ level, ** — significant at $5 \%$ level, * — significant at $10 \%$ level 


\section{Appendix: Mixed Strategy Equilibrium for Tournament Stage}

Che and Gale (2000) characterize the mixed strategy equilibria of "difference form contests" in which the contest success function for player $i$ (i.e., player $i$ 's probability of winning) is given by $f\left(\left\{g\left(e_{i}\right)-g\left(e_{j}\right)\right\}_{i \neq j}\right)$ as in our tournament stage. Much of their attention is restricted to a specific success function: $f\left(e_{i}-e_{j}\right)=\max \left\{\min \left\{\frac{1}{2}+s\left(e_{i}-e_{j}\right), 1\right\}, 0\right\}$, where $e_{i}$ is the "bid" (i.e., effort) of player $i$, while $s$ is the rate at which player $i$ 's probability of winning is increasing in his bid. Player $i$ can guarantee winning by submitting a bid that is at least $\frac{1}{2 s}$ greater than the bid of his rival. This contest success function is sufficient for our purposes as well. Our problem is identical to that in Che and Gale's Proposition 3 with two exceptions: 1) contest losers in our environment have a positive payout, and 2) our cost function $\left(C(e)=10 e^{2}\right)$ is convex rather than linear. ${ }^{12}$

Che and Gale propose the following mixed strategy equilibrium:

Agent $j$ assigns masses $n_{1}, n_{2}, \ldots, n_{k}$ to bids $e_{j, 1}, e_{j, 2}, \ldots, e_{j, k}$, while bidder $i$ assigns masses $m_{1}, m_{2}, \ldots, m_{k}$ to bids $e_{i, 1}, e_{i, 2}, \ldots, e_{i, k} . \quad$ Suppose that $e_{i, 1}=0, e_{j, 1}=0, e_{i, 2} \in\left[\frac{1}{2 s}, \frac{1}{s}\right], e_{j, 2} \in$ $\left[\frac{1}{2 s}, \frac{1}{s}\right]$ and $e_{i, d}-e_{i, d-1}=e_{j, d}-e_{j, d-1}=\frac{1}{s}$ for $d=3,4, \ldots, k$. For any $e_{i} \geq 0$, let $i(e) \in$ $\operatorname{argmin}_{j}\left|e_{i}-e_{j}\right|$ be the index of the $e_{j}$ closest to $e_{i}$, while $j(e)$ is analogously defined.

For notational simplicity, $\Lambda=\mu\left[\frac{1}{2}\left(W+E \pi_{W}^{*}\right)+\frac{1}{2}\left(L+E \pi_{L}^{*}\right)\right]+(1-\mu)\left(L+E \pi_{L}^{*}\right)$ and $\Omega=(1-\mu)\left(W+E \pi_{W}^{*}-L-E \pi_{L}^{*}\right)$. If agents play the suggested equilibrium strategies, the payoff to agent $i$ from bidding $e_{i} \geq 0$ is then $U_{i}\left(e_{i}\right)=$

\footnotetext{
${ }^{12}$ The payoff to the winner of our contest is strictly positive and corresponds to the bidder's value, $v$, in Che and Gale.
} 


$$
\begin{array}{cc}
\Omega n_{1}\left[\frac{1}{2}+s e_{i}\right]+\Lambda-C(x) & \text { if } e_{i} \leq e_{j, 2}-\frac{1}{2 s} \\
\Omega\left\{n_{1}\left[\frac{1}{2}+s e_{i}\right]+n_{2}\left[\frac{1}{2}+s\left(e_{i}-e_{j, 2}\right)\right]\right\}+\Lambda-C(x) & \text { if } e_{i} \in\left[e_{j, 2}-\frac{1}{2 s}, \frac{1}{2 s}\right] \\
\Omega\left\{\sum_{d=1}^{i(e)-1} n_{d}+n_{i(e)}\left[\frac{1}{2}+s\left(e_{i}-e_{j, i(x)}\right)\right]\right\}+\Lambda-C(x) & \text { if } e_{i} \in\left[\frac{1}{2 s}, e_{j, k}+\frac{1}{2 s}\right] \\
\Omega+\mathrm{L}-C(x) & \text { if } e_{i} \geq e_{j, k}+\frac{1}{2 s}
\end{array}
$$

Several conditions are necessary for these to be equilibrium strategies. First, the bidder must attain local maxima at $e_{i, 1}, e_{i, 2}, \ldots, e_{i, k}$. A sufficient condition for this is that

$$
U_{i}^{\prime}\left(e_{i, d}\right)=\Omega n_{d} s-C^{\prime}\left(e_{i, d}\right)=0 \forall d=2, \ldots, k
$$

which implies that $n_{d}=\frac{C^{\prime}\left(e_{i, d}\right)}{\Omega s}$. Second, the assumption that $e_{i, 1}=0$ implies that an agent cannot raise his payoff if he increases his bid from zero, i.e.,

$$
U_{i}^{\prime}(0)=\Omega n_{1} s-C^{\prime}(0) \leq 0
$$

Finally, it must be the case that the mass sums to one,

$$
n_{1}=1-\frac{\sum_{d=2}^{k} C^{\prime}\left(e_{i, d}\right)}{\Omega s}
$$

The fact that an agent must be indifferent between $e_{i, f}$ and $e_{i, g}(f \neq g)$ pins down the locations of all mass points.

Proof: Che and Gale use a proof by construction to show that that this is an equilibrium when costs are linear. The proof goes through trivially with the convex cost function we use: $U_{i}\left(e_{i}\right)$ is decreasing when $e_{i} \in\left[0, e_{j, 2}-\frac{1}{2 s}\right], U_{i}\left(e_{i}\right)$ is (weakly) increasing when $e_{i} \in\left[e_{j, 2}-\frac{1}{2 s}, \frac{1}{2 s}\right]$, $U_{i}\left(e_{i}\right)$ is constant when $e_{i} \in\left[\frac{1}{2 s}, e_{j, k}+\frac{1}{2 s}\right]$, and $U_{i}\left(e_{i}\right)$ is decreasing whenever $e_{i} \geq e_{j, k}+\frac{1}{2 s}$. 
Finally, $U_{i}(0)=U_{i}\left(e_{i}\right)$ for all $e_{i} \in\left[\frac{1}{2 s}, e_{j, k}+\frac{1}{2 s}\right]$. Our agents are symmetric, so $e_{i, d}=$ $e_{j, d}$ and $n_{d}=m_{d} \forall d=1, \ldots, k$.

Having shown that this is an equilibrium, we can pin down the exact equilibrium. Equation (1) implies that $\Omega n_{1} s \leq 0$. Given that $\Omega>0$ and $s>0$, this can only be true if $n_{1} \leq 0$. This means that equation (2) becomes $\Omega s \leq \sum_{d=2}^{k} C^{\prime}\left(e_{i, d}\right)$, which yields the value of $e_{i, k}$, the largest effort level on which an agent places mass (i.e., $\bar{e}$ ). Finally, when we set $U_{i}(0)=$ $U_{i}\left(e_{i, d}\right)$, we find that $e_{i, 2}=\frac{1}{s}$.

In all treatments, $W=162, L=90$, and $s=15.15$. In all treatments other than the baseline, $\mu=0.75 ; \mu=0$ in the baseline. Finally, we need to solve for the optimal production stage effort to get $E \pi_{W}^{*}$ and $E \pi_{L}^{*}$. The production stage problem for the tournament loser is

$$
\max _{e_{L}} \alpha\left(120 e_{L}\right)-10 e_{L}^{2}
$$

The production stage problem for the tournament winner is

$$
\max _{e_{W}} \alpha\left(120 e_{W}\right)+\beta\left(120 e_{L}\right)-10 e_{W}^{2}
$$

The first-order condition, regardless of whether one is a winner or loser is $120 \alpha-20 e=0$, such that $e^{*}=2$. Substituting this value into (3) and (4) yields $E \pi_{W}^{*}=88$ and $E \pi_{L}^{*}=48$. With these parameter values, we can solve for the exact mixed strategies. ${ }^{13}$

\footnotetext{
13 Bearing in mind that for the repeated production stage treatment, $\Lambda=\mu\left[\frac{1}{2}\left(W+4 E \pi_{W}^{*}\right)+\right.$ $\left.\frac{1}{2}\left(L+4 E \pi_{L}^{*}\right)\right]+(1-\mu)\left(L+E \pi_{L}^{*}\right)$ and $\Omega=(1-\mu)\left(W+4 E \pi_{W}^{*}-L-4 E \pi_{L}^{*}\right)$
} 


\section{Appendix: Instructions}

\section{INSTRUCTIONS (LinKed PAYOFFs)}

This portion of the experiment will consist of 40 periods consisting of two stages each. At the beginning of the session, you will be assigned a color, either Red or Blue. Half of all players will be Red, and half will be Blue. The role these colors play will be explained shortly.

At the beginning of each period, you will be randomly paired with another subject of the opposite color. You will be paired with this subject for both stages of the period and then rematched with a different subject at the beginning of the next period. The basic structure is as follows:

\section{Stage 1}

Both you and the other subject will be producing output by choosing an "effort" level which is explained below. Your output will be determined by the following production function

$$
\text { Output }=120 * \text { effort }+ \text { noise }
$$

where effort is the level of effort you choose and noise is a random number. The noise term will be drawn from a uniform distribution over the interval $[-2,2]$. This means that any number between -2 and 2 is equally likely to be the random term added to your output. Note that sometimes this random term will increase your output, sometimes it will decrease it, and sometimes it will neither increase nor decrease your output.

You can choose any level of effort between 0 and 6 in increments of 0.01 . That is, your effort choice cannot have any more than 2 numbers after the decimal point. Effort is not free. The cost to you of effort is determined by the following cost function

$$
\text { Cost }=10 * \text { effort }^{2}
$$

These costs are expressed in terms of experimental currency units (ECUs). This cost of effort will be deducted from your earnings as explained below. Once you and the subject you are paired with have chosen effort levels, the computer will compare the output produced by you and the other subject. If you produce more than your partner during the first stage, then you will receive a payment of 162 ECUs, while if you produce less output than your partner you will receive a payment of 90 ECUs. The exchange rate will be \$1=20 ECUs. Your total earnings for stage 1 will be

$$
\text { Earnings }=\text { Payment }- \text { Cost of effort }
$$

There will be a calculator on the screen that you can use to determine how much a given level of effort will cost and what your potential output would be for a given effort level. You use the calculator by entering an amount of effort and clicking the "Calculate" button. You submit your 
effort choice by clicking the "Submit" button. Once you click the Submit button, YOUR EFFORT CHOICE IS BINDING AND CANNOT BE CHANGED.

\section{Stage 2}

In stage 2, you will produce output by choosing effort in exactly the same way as in stage 1 . The production function, cost of effort, and distribution for the noise term will be exactly the same. In this stage, however, the player who received the payment of 90 ECUs in stage 1 will earn $\frac{1}{3}$ of the output he/she produces in stage 2 . So if the player produces 180 units of output, he will receive a payment of 60 ECUs. The player who received the payment of 162 in the first stage will also receive $\frac{1}{3}$ of his/her own output in the second stage plus $\frac{1}{5}$ of the output produced by the other player in stage 2 .

Example 1:

Suppose you supply 1.85 units of effort in the first stage and the noise term you draw is -0.5 , your output will be

$$
\text { Output }=120 * 1.85-0.5=221.5
$$

and your costs will be

$$
\text { Cost }=10 * 1.85^{2}=34.22
$$

Suppose your output is higher than that of the player with whom you are paired, your earnings will be

$$
\text { Earnings }=162-34.22=127.78
$$

Suppose you supply 0.99 units of effort in the second stage and the noise term you draw is 1.4. Your output will be

$$
\text { Output }=120 * 0.99+1.4=120.2
$$

and your costs will be

$$
\text { Cost }=10 * 0.99^{2}=9.8
$$

The player you are paired with supplies 2.1 units of effort in the second stage and the noise term he draws is 0.7 , his output will be

$$
\text { Output }=120 * 2.1+0.7=252.7
$$

Because your output was higher in the first stage, you will receive $\frac{1}{3}$ of your output in the second stage AND $\frac{1}{5}$ of the other player's output in the second stage, so your earnings in the second 
stage will be

$$
\text { Earnings }=\frac{1}{3}(120.2)+\frac{1}{5}(252.7)-9.8=90.61
$$

\section{Example 2:}

Suppose you supply 1.9 units of effort in the first stage and the noise term you draw is 0.2 , your output will be

$$
\text { Output }=120 * 1.9+0.2=228.2
$$

and your costs will be

$$
\text { Cost }=10 * 1.9^{2}=39.6
$$

Suppose your output is lower than that of the player with whom you are paired, your earnings will be

$$
\text { Earnings }=90-39.6=50.4
$$

Suppose you supply 1.67 units of effort in the second stage and the noise term you draw is 0 . Your output will be

$$
\text { Output }=120 * 1.67+0=200.4
$$

and your costs will be

$$
\text { Cost }=10 * 1.67^{2}=27.89
$$

Because your output was lower in the first stage, you will only receive $\frac{1}{3}$ of your output in the second stage, so your earnings in the second stage will be

$$
\text { Earnings }=\frac{1}{3}(200.4)-27.89=38.91
$$

\section{The Role of Colors}

In most periods, the stages will proceed as explained above. However, in every period there is a $25 \%$ chance that the computer will disregard the outputs produced by you and the player you are paired with in the first stage. In these cases - on average about 10 of the 40 periods we will conduct today — the computer will assign the first stage payments (162 and 90 ECUs) based on colors. In every period in which it disregards first-stage outputs when determining first-stage payments, there is a 50-50 chance that the computer will assign the payment of $162 \mathrm{ECU}$ to the Red player and 90 to the Blue player and a 50-50 chance that it will assign the payment of 162 ECU to the Blue player and 90 to the Red player. You will not be made aware of whether the computer has disregarded the outputs or if it has assigned the higher payment to your color until 
AFTER you have made your effort decision. You will pay for your first stage effort regardless of whether the computer uses your first stage output to determine payoffs.

When colors are used to assign payments in the first stage, the amount you receive in the second stage will also be determined by which payment the computer assigned you in the first stage. If you were assigned the payment of 90 ECUs in the first stage, then you will receive $1 / 3$ of your second stage output regardless of whether your effort choice resulted in higher or lower output in the first stage. Similarly, if you were assigned the payment of 162 ECUs, you will receive $1 / 3$ of your second stage output and 1/5 of the other player's second stage output regardless of whether your effort choice resulted in higher or lower output in the first stage.

\section{Example 3:}

Suppose your color is Red and you supply 1.85 units of effort in the first stage and the noise term you draw is -0.5 , your output will be

$$
\text { Output }=120 * 1.85-0.5=221.5
$$

and your costs will be

$$
\text { Cost }=10 * 1.85^{2}=34.22
$$

Suppose the other (Blue) player's output is 200.01. Your output is higher, but the computer disregards your outputs and assigns the Blue player the payment of 162. You are the Red player, so your earnings will be

$$
\text { Earnings }=90-34.22=55.78
$$

Suppose you supply 0.99 units of effort in the second stage and the noise term you draw is 1.4. Your output will be

$$
\text { Output }=120 * 0.99+1.4=120.2
$$

and your costs will be

$$
\text { Cost }=10 * 0.99^{2}=9.8
$$

Even though your output was higher in the first round, because of the computer's decision, you will only receive $\frac{1}{3}$ of your output in the second stage WHILE the other player will receive $\frac{1}{5}$ of your output in the second stage as well as $\frac{1}{3}$ of his own output, so your earnings in the second stage will be 


$$
\text { Earnings }=\frac{1}{3}(120.2)-9.8=30.27
$$

We will play 40 rounds. You will be paid for 2 randomly selected rounds out of the 40 and you will not learn which rounds have been selected until all 40 periods have been completed.

Following the completion of all 40 rounds, you will be asked to answer a short questionnaire, part of which you will be paid for, before being paid your total earnings and dismissed. In addition to your earnings from the experiment, all subjects will receive a $\$ 5$ show-up fee. Are there any questions? 


\section{INSTRUCTIONS (ROTATING MANAGERS)}

This portion of the experiment will consist of 40 periods consisting of two stages each. At the beginning of the session, you will be assigned a color, either Red or Blue. Half of all players will be Red, and half will be Blue. The role these colors play will be explained shortly.

In the first stage of each period, you will be randomly paired with another subject of the opposite color. You will be paired with this subject for the first stage and then matched with a different subject at the beginning of the second stage in a manner explained below. The basic structure is as follows:

\section{Stage 1}

Both you and the subject with whom you are paired will be producing output by choosing an "effort” level which is explained below. Your output will be determined by the following production function

$$
\text { Output }=120 * \text { effort }+ \text { noise }
$$

where effort is the level of effort you choose and noise is a random number. The noise term will be drawn from a uniform distribution over the interval $[-2,2]$. This means that any number between -2 and 2 is equally likely to be the random term added to your output. Note that sometimes this random term will increase your output, sometimes it will decrease it, and sometimes it will neither increase nor decrease your output.

You can choose any level of effort between 0 and 6 in increments of 0.01 . That is, your effort choice cannot have any more than 2 numbers after the decimal point. Effort is not free. The cost to you of effort is determined by the following cost function

$$
\text { Cost }=10 * \text { effort }^{2}
$$

These costs are expressed in terms of experimental currency units (ECUs). This cost of effort will be deducted from your earnings as explained below. Once you and the subject with whom you are paired have chosen effort levels, the computer will compare the output produced by you and the other subject. If you produce more than your partner during the first stage, then you will receive a payment of 162 ECUs, while if you produce less output than your partner you will receive a payment of 90 ECUs. The exchange rate will be $\$ 1=20$ ECUs. Your total earnings for stage 1 will be

$$
\text { Earnings }=\text { Payment }- \text { Cost of effort }
$$

There will be a calculator on the screen that you can use to determine how much a given level of effort will cost and what your potential output would be for a given effort level. You use the calculator by entering an amount of effort and clicking the "Calculate" button. You submit your 
effort choice by clicking the "Submit" button. Once you click the Submit button, YOUR EFFORT CHOICE IS BINDING AND CANNOT BE CHANGED.

\section{Stage 2}

In stage 2, you will be matched with a different subject. Although you are matched with a different subject, each pair of subjects will always have one player who received the payment of 162 in the first stage and one player who received the payment of 90 in the first stage.

You will produce output by choosing effort in exactly the same way as in stage 1 . The production function, cost of effort, and distribution for the noise term will be exactly the same. In this stage, however, the player who received the payment of 90 ECUs in stage 1 -the player who produced less than his/her partner in the first stage-will earn $\frac{1}{3}$ of the output he/she produces in stage 2. So if the player produces 180 units of output, he will receive a payment of 60 ECUs. The player who received the payment of 162 in the first stage - the player who produced more output than his/her partner in the first stage—-will also receive $\frac{1}{3}$ of his/her own output in the second stage plus $\frac{1}{5}$ of the output produced by his/her new partner in stage 2 .

\section{Example 1:}

Suppose you supply 1.85 units of effort in the first stage and the noise term you draw is -0.5 , your output will be

$$
\text { Output }=120 * 1.85-0.5=221.5
$$

and your costs will be

$$
\text { Cost }=10 * 1.85^{2}=34.22
$$

Suppose your output is higher than that of the player with whom you are paired in the first stage, your earnings will be

$$
\text { Earnings }=162-34.22=127.78
$$

Suppose you supply 0.99 units of effort in the second stage and the noise term you draw is 1.4. Your output will be

$$
\text { Output }=120 * 0.99+1.4=120.2
$$

and your costs will be

$$
\text { Cost }=10 * 0.99^{2}=9.8
$$


After being matched with a new partner at the start of the second stage, the player you are paired with in the second stage supplies 2.1 units of effort in the second stage and the noise term he draws is 0.7 , his output will be

$$
\text { Output }=120 * 2.1+0.7=252.7
$$

Because your output was higher than that of the person with whom you were paired in the first stage, you will receive $\frac{1}{3}$ of your output in the second stage AND $\frac{1}{5}$ of the output of the player with whom you are paired in the second stage, so your earnings in the second stage will be

$$
\text { Earnings }=\frac{1}{3}(120.2)+\frac{1}{5}(252.7)-9.8=90.61
$$

\section{Example 2:}

Suppose you supply 1.9 units of effort in the first stage and the noise term you draw is 0.2 , your output will be

$$
\text { Output }=120 * 1.9+0.2=228.2
$$

and your costs will be

$$
\text { Cost }=10 * 1.9^{2}=39.6
$$

Suppose your output is lower than that of the player with whom you are paired in the first stage, your earnings will be

$$
\text { Earnings }=90-39.6=50.4
$$

Suppose you supply 1.67 units of effort in the second stage and the noise term you draw is 0 . Your output will be

$$
\text { Output }=120 * 1.67+0=200.4
$$

and your costs will be

$$
\text { Cost }=10 * 1.67^{2}=27.89
$$

Because your output was lower than that of the person with whom you were paired in the first stage, you will only receive $\frac{1}{3}$ of your output in the second stage, so your earnings in the second stage will be

$$
\text { Earnings }=\frac{1}{3}(200.4)-27.89=38.91
$$

\section{The Role of Colors}

In most periods, the stages will proceed as explained above. However, in every period there is a $25 \%$ chance that the computer will disregard the outputs produced by you and the player you are paired with in the first stage. In these cases - on average about 10 of the 40 periods we will 
conduct today — the computer will assign the first stage payments (162 and 90 ECUs) based on colors. In every period in which it disregards first-stage outputs when determining first-stage payments, there is a 50-50 chance that the computer will assign the payment of 162 ECU to the Red player and 90 to the Blue player and a 50-50 chance that it will assign the payment of 162 ECU to the Blue player and 90 to the Red player. You will not be made aware of whether the computer has disregarded the outputs or if it has assigned the higher payment to your color until AFTER you have made your effort decision. You will pay for your first stage effort regardless of whether the computer uses your first stage output to determine payoffs.

When colors are used to assign payments in the first stage, the amount you receive in the second stage will also be determined by which payment the computer assigned you in the first stage. If you were assigned the payment of 90 ECUs in the first stage, then you will receive 1/3 of your second stage output regardless of whether your effort choice resulted in higher or lower output in the first stage. Similarly, if you were assigned the payment of 162 ECUs, you will receive 1/3 of your second stage output and 1/5 of second stage output of the player with whom you are paired in the second stage regardless of whether your effort choice resulted in higher or lower output in the first stage. If you were assigned the payment of 90 ECUs in the first stage because of your color, you will be matched with a player who was assigned 162 ECUs in the first stage and vice versa.

Example 3:

Suppose your color is Red and you supply 1.85 units of effort in the first stage and the noise term you draw is -0.5 , your output will be

$$
\text { Output }=120 * 1.85-0.5=221.5
$$

and your costs will be

$$
\text { Cost }=10 * 1.85^{2}=34.22
$$

Suppose the other (Blue) player's output is 200.01. Your output is higher, but the computer disregards your outputs and assigns the Blue player the payment of 162. You are the Red player, so your earnings will be

$$
\text { Earnings }=90-34.22=55.78
$$

You received 90 ECUs in the first stage and are now matched with a new player who received 162 ECUs in the first stage also because of his/her color. Suppose you supply 0.99 units of effort in the second stage and the noise term you draw is 1.4. Your output will be

$$
\text { Output }=120 * 0.99+1.4=120.2
$$

and your costs will be 


$$
\text { Cost }=10 * 0.99^{2}=9.8
$$

Even though your output was higher in the first round, because of the computer's decision, you will only receive $\frac{1}{3}$ of your output in the second stage WHILE the player with whom you are now paired will receive $\frac{1}{3}$ of his/her own output and $\frac{1}{5}$ of your output in the second stage because he/she was awarded the payment of 162 ECUs in the first stage. Your earnings in the second stage will be

$$
\text { Earnings }=\frac{1}{3}(120.2)-9.8=30.27
$$

We will play 40 periods. You will be paid for 2 randomly selected periods out of the 40 and you will not learn which periods have been selected until all 40 periods have been completed. Following the completion of all 40 periods, you will be asked to answer a short questionnaire, part of which you will be paid for, before being paid your total earnings and dismissed. In addition to your earnings from the experiment, all subjects will receive a $\$ 5$ show-up fee. Are there any questions? 


\section{Instructions (Repeated Production Stage)}

This portion of the experiment will consist of 30 periods consisting of five stages each. At the beginning of the session, you will be assigned a color, either Red or Blue. Half of all players will be Red, and half will be Blue. The role these colors play will be explained shortly.

At the beginning of each period, you will be randomly paired with another subject of the opposite color. You will be paired with this subject for all five stages of the period and then matched with a different subject also of the opposite color at the beginning of the next period. The basic structure is as follows:

\section{Stage 1}

Both you and the subject with whom you are paired will be producing output by choosing an "effort" level which is explained below. Your output will be determined by the following production function

$$
\text { Output }=120 * \text { effort }+ \text { noise }
$$

where effort is the level of effort you choose and noise is a random number. The noise term will be drawn from a uniform distribution over the interval [-2, 2]. This means that any number between -2 and 2 is equally likely to be the random term added to your output. Note that sometimes this random term will increase your output, sometimes it will decrease it, and sometimes it will neither increase nor decrease your output.

You can choose any level of effort between 0 and 6 in increments of 0.01 . That is, your effort choice cannot have any more than 2 numbers after the decimal point. Effort is not free. The cost to you of effort is determined by the following cost function

$$
\text { Cost }=10 * \text { effort }^{2}
$$

These costs are expressed in terms of experimental currency units (ECUs). This cost of effort will be deducted from your earnings as explained below. Once you and the subject you are paired with have chosen effort levels, the computer will compare the output produced by you and the other subject. If you produce more than your partner during the first stage, then you will receive a payment of 162 ECUs, while if you produce less output than your partner you will receive a payment of 90 ECUs. The exchange rate will be $\$ 1=20$ ECUs. Your total earnings for stage 1 will be

$$
\text { Earnings }=\text { Payment }- \text { Cost of effort }
$$

There will be a calculator on the screen that you can use to determine how much a given level of effort will cost and what your potential output would be for a given effort level. You use the calculator by entering an amount of effort and clicking the "Calculate" button. You submit your 
effort choice by clicking the "Submit" button. Once you click the Submit button, YOUR EFFORT CHOICE IS BINDING AND CANNOT BE CHANGED.

\section{Stages 2-5}

In stages 2-5, you will produce output by choosing effort in exactly the same way as in stage 1 . The production function, cost of effort, and distribution for the noise term will be exactly the same. In each of these four stages, however, the player who received the payment of 90 ECUs in stage 1 will earn $\frac{1}{3}$ of the output he/she produces in the stage. So if the player produces 180 units of output, he will receive a payment of 60 ECUs. The player who received the payment of 162 in the first stage will also receive $\frac{1}{3}$ of his/her own output in any given stage plus $\frac{1}{5}$ of the output produced by the other player in that stage. Your earnings for a period will be the sum of your earnings from the five stages.

Example 1:

Suppose you supply 1.85 units of effort in the first stage and the noise term you draw is -0.5 , your output will be

$$
\text { Output }=120 * 1.85-0.5=221.5
$$

and your costs will be

$$
\text { Cost }=10 * 1.85^{2}=34.22
$$

Suppose your output is higher than that of the player with whom you are paired, your earnings will be

$$
\text { Earnings }=162-34.22=127.78
$$

Suppose you supply 0.99 units of effort in the second stage and the noise term you draw is 1.4. Your output will be

$$
\text { Output }=120 * 0.99+1.4=120.2
$$

and your costs will be

$$
\text { Cost }=10 * 0.99^{2}=9.8
$$

The player you are paired with supplies 2.1 units of effort in the second stage and the noise term he draws is 0.7 , his output will be

$$
\text { Output }=120 * 2.1+0.7=252.7
$$


Because your output was higher in the first stage, you will receive $\frac{1}{3}$ of your output in the second stage AND $\frac{1}{5}$ of the other player's output in the second stage, so your earnings in the second stage will be

$$
\text { Earnings }=\frac{1}{3}(120.2)+\frac{1}{5}(252.7)-9.8=90.61
$$

Your earnings in stages 3, 4, and 5 are determined in exactly the same way as those in period 2. Note that your earnings in stages 2 through 5 depend on whether you produce more or less than your partner in stage 1 .

Example 2:

Suppose you supply 1.9 units of effort in the first stage and the noise term you draw is 0.2, your output will be

$$
\text { Output }=120 * 1.9+0.2=228.2
$$

and your costs will be

$$
\text { Cost }=10 * 1.9^{2}=39.6
$$

Suppose your output is lower than that of the player with whom you are paired, your earnings will be

$$
\text { Earnings }=90-39.6=50.4
$$

Suppose you supply 1.67 units of effort in the second stage and the noise term you draw is 0 . Your output will be

$$
\text { Output }=120 * 1.67+0=200.4
$$

and your costs will be

$$
\text { Cost }=10 * 1.67^{2}=27.89
$$

Because your output was lower in the first stage, you will only receive $\frac{1}{3}$ of your output in the second stage, so your earnings in the second stage will be

$$
\text { Earnings }=\frac{1}{3}(200.4)-27.89=38.91
$$

Again, your earnings in stages 3, 4, and 5 are determined in exactly the same way as those in period 2.

\section{The Role of Colors}

In most periods, the stages will proceed as explained above. However, in every period there is a $25 \%$ chance that the computer will disregard the outputs produced by you and the player you are paired with in the first stage. In these cases — on average about 7-8 of the 30 periods we will 
conduct today — the computer will assign the first stage payments (162 and 90 ECUs) based on colors. In every period in which it disregards first-stage outputs when determining first-stage payments, there is a 50-50 chance that the computer will assign the payment of 162 ECU to the Red player and 90 to the Blue player and a 50-50 chance that it will assign the payment of 162 ECU to the Blue player and 90 to the Red player. You will not be made aware of whether the computer has disregarded the outputs or if it has assigned the higher payment to your color until AFTER you have made your effort decision. You will pay for your first stage effort regardless of whether the computer uses your first stage output to determine payoffs.

When colors are used to assign payments in the first stage, the amounts you receive in stages 2 , 3, 4 and 5 will also be determined by which payment the computer assigned you in the first stage. If you were assigned the payment of 90 ECUs in the first stage, then you will receive 1/3 of your output in each subsequent stage regardless of whether your effort choice resulted in higher or lower output in the first stage. Similarly, if you were assigned the payment of 162 ECUs, you will receive 1/3 of your output and 1/5 of the other player's output in each subsequent stage regardless of whether your effort choice resulted in higher or lower output in the first stage.

\section{Example 3:}

Suppose your color is Red and you supply 1.85 units of effort in the first stage and the noise term you draw is -0.5 , your output will be

$$
\text { Output }=120 * 1.85-0.5=221.5
$$

and your costs will be

$$
\text { Cost }=10 * 1.85^{2}=34.22
$$

Suppose the other (Blue) player's output is 200.01. Your output is higher, but the computer disregards your outputs and assigns the Blue player the payment of 162. You are the Red player, so your earnings will be

$$
\text { Earnings }=90-34.22=55.78
$$

Suppose you supply 0.99 units of effort in the second stage and the noise term you draw is 1.4. Your output will be

$$
\text { Output }=120 * 0.99+1.4=120.2
$$

and your costs will be

$$
\text { Cost }=10 * 0.99^{2}=9.8
$$

Even though your output was higher in the first round, because of the computer's decision, you will only receive $\frac{1}{3}$ of your output in the second stage WHILE the other player will receive $\frac{1}{5}$ of your output in the second stage as well as $\frac{1}{3}$ of his own output, so your earnings in the second 
stage will be

$$
\text { Earnings }=\frac{1}{3}(120.2)-9.8=30.27
$$

Again, your earnings in stages 3, 4, and 5 are determined in exactly the same way as those in period 2.

We will play 30 periods. You will be paid for 2 randomly selected periods out of the 30 and you will not learn which periods have been selected until all 30 periods have been completed.

Following the completion of all 30 periods, you will be asked to answer a short questionnaire, part of which you will be paid for, before being paid your total earnings and dismissed. In addition to your earnings from the experiment, all subjects will receive a $\$ 5$ show-up fee. Are there any questions? 


\section{INSTRUCTIONS (BASELINE)}

This portion of the experiment will consist of 40 periods consisting of two stages each. At the beginning of the session, you will be assigned a color, either Red or Blue. Half of all players will be Red, and half will be Blue.

At the beginning of each period, you will be randomly paired with another subject of the opposite color. You will be paired with this subject for the first stage of the period and then rematched with a different subject at the beginning of the next period. The basic structure is as follows:

\section{Stage 1}

Both you and the other subject will be producing output by choosing an "effort" level which is explained below. Your output will be determined by the following production function

$$
\text { Output }=120 * \text { effort }+ \text { noise }
$$

where effort is the level of effort you choose and noise is a random number. The noise term will be drawn from a uniform distribution over the interval $[-2,2]$. This means that any number between -2 and 2 is equally likely to be the random term added to your output. Note that sometimes this random term will increase your output, sometimes it will decrease it, and sometimes it will neither increase nor decrease your output.

You can choose any level of effort between 0 and 6 in increments of 0.01 . That is, your effort choice cannot have any more than 2 numbers after the decimal point. Effort is not free. The cost to you of effort is determined by the following cost function

$$
\text { Cost }=10 * \text { effort }{ }^{2}
$$

These costs are expressed in terms of experimental currency units (ECUs). This cost of effort will be deducted from your earnings as explained below. Once you and the subject you are paired with have chosen effort levels, the computer will compare the output produced by you and the other subject. If you produce more than your partner during the first stage, then you will receive a payment of 162 ECUs, while if you produce less output than your partner you will receive a payment of 90 ECUs. The exchange rate will be $\$ 1=20$ ECUs. Your total earnings for stage 1 will be

$$
\text { Earnings }=\text { Payment }- \text { Cost of effort }
$$

There will be a calculator on the screen that you can use to determine how much a given level of effort will cost and what your potential output would be for a given effort level. You use the calculator by entering an amount of effort and clicking the "Calculate" button. You submit your 
effort choice by clicking the "Submit" button. Once you click the Submit button, YOUR EFFORT CHOICE IS BINDING AND CANNOT BE CHANGED.

\section{Stage 2}

In stage 2, you will produce output by choosing effort in exactly the same way as in stage 1 . The production function, cost of effort, and distribution for the noise term will be exactly the same. In this stage, however, you earnings will be $\frac{1}{3}$ of the output you produce in stage 2 .

Example 1:

Suppose you supply 1.85 units of effort in the first stage and the noise term you draw is -0.5 , your output will be

$$
\text { Output }=120 * 1.85-0.5=221.5
$$

and your costs will be

$$
\text { Cost }=10 * 1.85^{2}=34.22
$$

Suppose your output is higher than that of the player with whom you are paired, your earnings will be

$$
\text { Earnings }=162-34.22=127.78
$$

Suppose you supply 0.99 units of effort in the second stage and the noise term you draw is 1.4. Your output will be

$$
\text { Output }=120 * 0.99+1.4=120.2
$$

and your costs will be

$$
\text { Cost }=10 * 0.99^{2}=9.8
$$

Your earnings in the second stage will be

$$
\text { Earnings }=\frac{1}{3}(120.2)-9.8=30.27
$$

Example 2:

Suppose you supply 1.9 units of effort in the first stage and the noise term you draw is 0.2 , your output will be

$$
\text { Output }=120 * 1.9+0.2=228.2
$$

and your costs will be 


$$
\text { Cost }=10 * 1.9^{2}=39.6
$$

Suppose your output is lower than that of the player with whom you are paired, your earnings will be

$$
\text { Earnings }=90-39.6=50.4
$$

Suppose you supply 1.67 units of effort in the second stage and the noise term you draw is 0 . Your output will be

$$
\text { Output }=120 * 1.67+0=200.4
$$

and your costs will be

$$
\text { Cost }=10 * 1.67^{2}=27.89
$$

Your earnings in the second stage will be

$$
\text { Earnings }=\frac{1}{3}(200.4)-27.89=38.91
$$

We will play 40 rounds. You will be paid for 2 randomly selected rounds out of the 40 and you will not learn which rounds have been selected until all 40 periods have been completed. Following the completion of all 40 rounds, you will be asked to answer a short questionnaire, part of which you will be paid for, before being paid your total earnings and dismissed. In addition to your earnings from the experiment, all subjects will receive a $\$ 5$ show-up fee. Are there any questions? 


\section{Appendix: Screen Shots of User Interface}

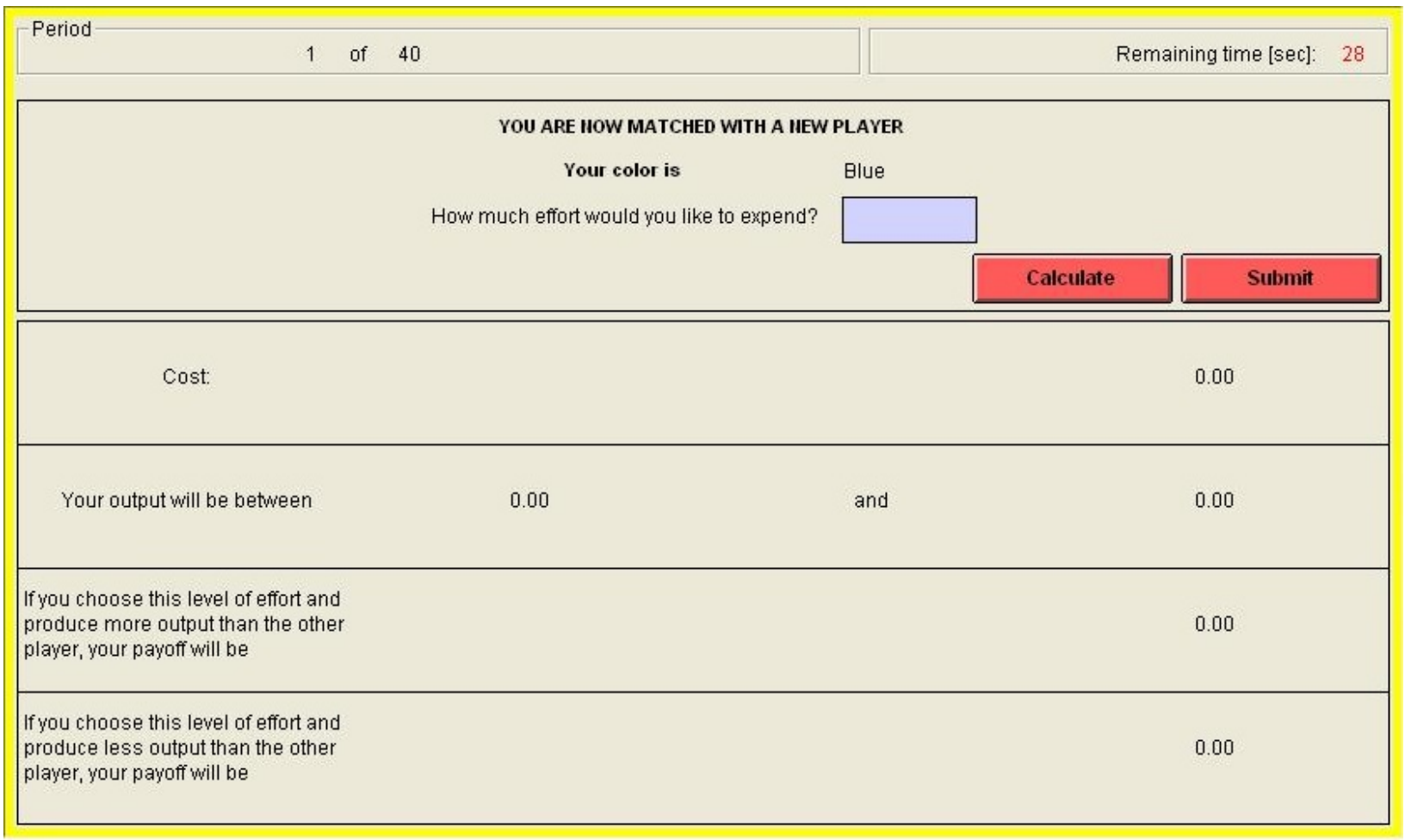

Figure A1 Tournament Interface 
Your color is

Blue

The output you produced in the first stage was higher than the output of the other player.

$\begin{array}{rc}\text { Your output in this stage is } & 10.90 \\ \text { The other player's output in this stage is } & 10.51 \\ \text { Your costs in the first stage are } & 0.10\end{array}$

Figure A2 Post-Tournament Feedback 
Your color is Blue

The computer has disregarded the first stage outputs and awarded the higher payment to the player whose color is BLUE.

The computer's random choice does not affect your outcome for the first stage.

Figure A3 Random Period Feedback When Allocation is Unaffected 
Your color is Red

The computer has disregarded the first stage outputs and awarded the higher payment to the player whose color is RED.

The computer's random choice changes the outcome of the first stage. Although your output was lower than the other player's in the first stage, you will receive 162 ECUs. In the next stage, you will receive 1/3 of your output AND 1/5 of the other player's output; the other player will receive $1 / 3$ of his output.

Figure A4 Feedback Screen When a Subject Wins Due to Randomness 
The computer has disregarded the first stage outputs and awarded the higher payment to the player whose color is RED.

The computer's random choice changes the outcome of the first stage. Although your output was higher than the other player's in the first stage, you will receive only 90 ECUs. In the next stage, you will receive $1 / 3$ of your output; the other player will receive $1 / 3$ of his output AND $1 / 5$ of your output.

Figure A5 Feedback When a Subject Loses Due to Randomness 
Your color is

Blue

You will receive $1 / 3$ of your output in the next stage. You will also receive an amount equal to $1 / 5$ of the other player's output.

$\begin{array}{rr}\text { Your output in the first stage was } & 10.90 \\ \text { The other player's output in this stage is } & 10.51 \\ \text { Your costs in the first stage were } & 0.10 \\ \text { Your net earnings in the first stage are } & 161.90\end{array}$

Figure A6 Payment Scheme Reminder Screen 


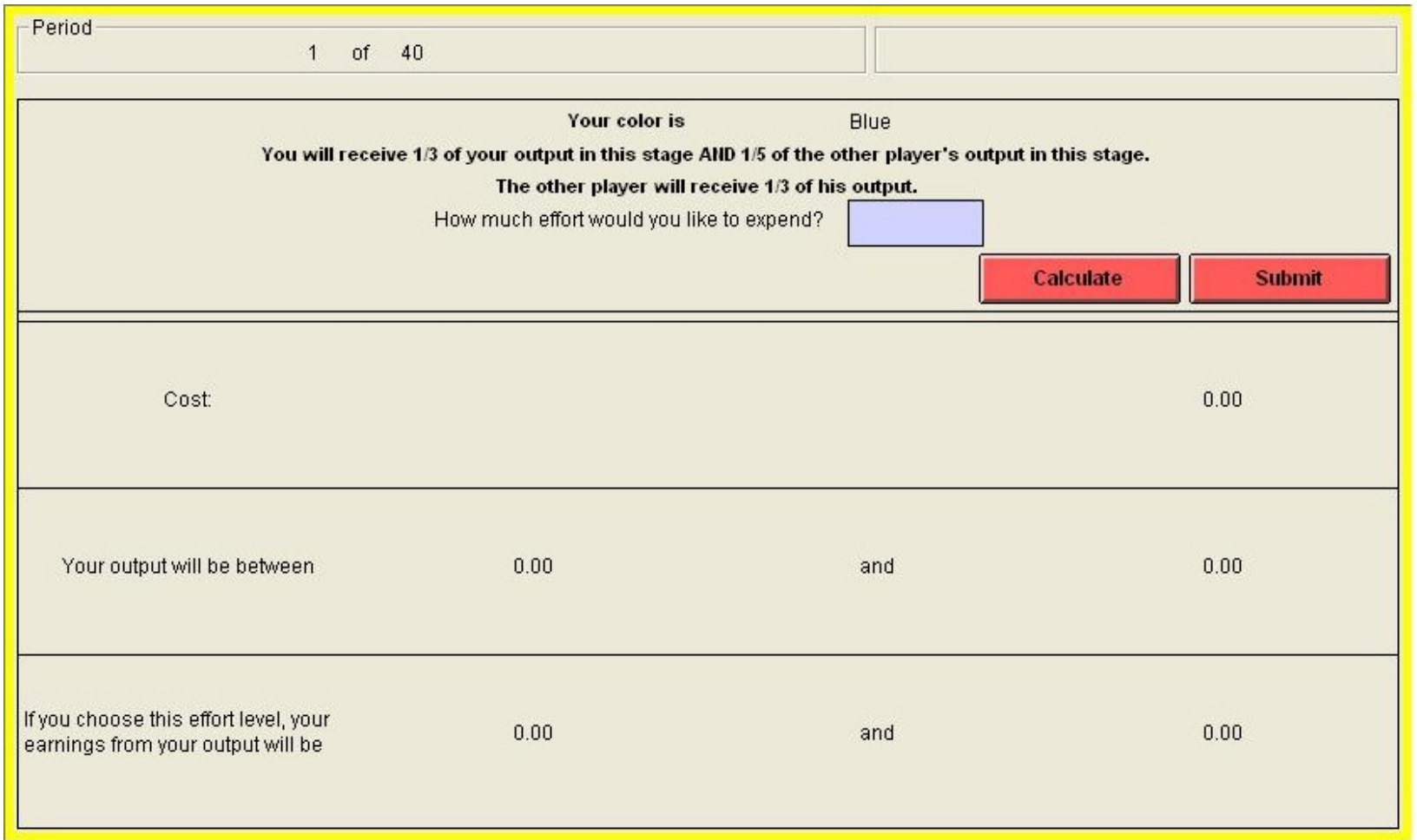

\section{Figure A7 Production Stage Interface}




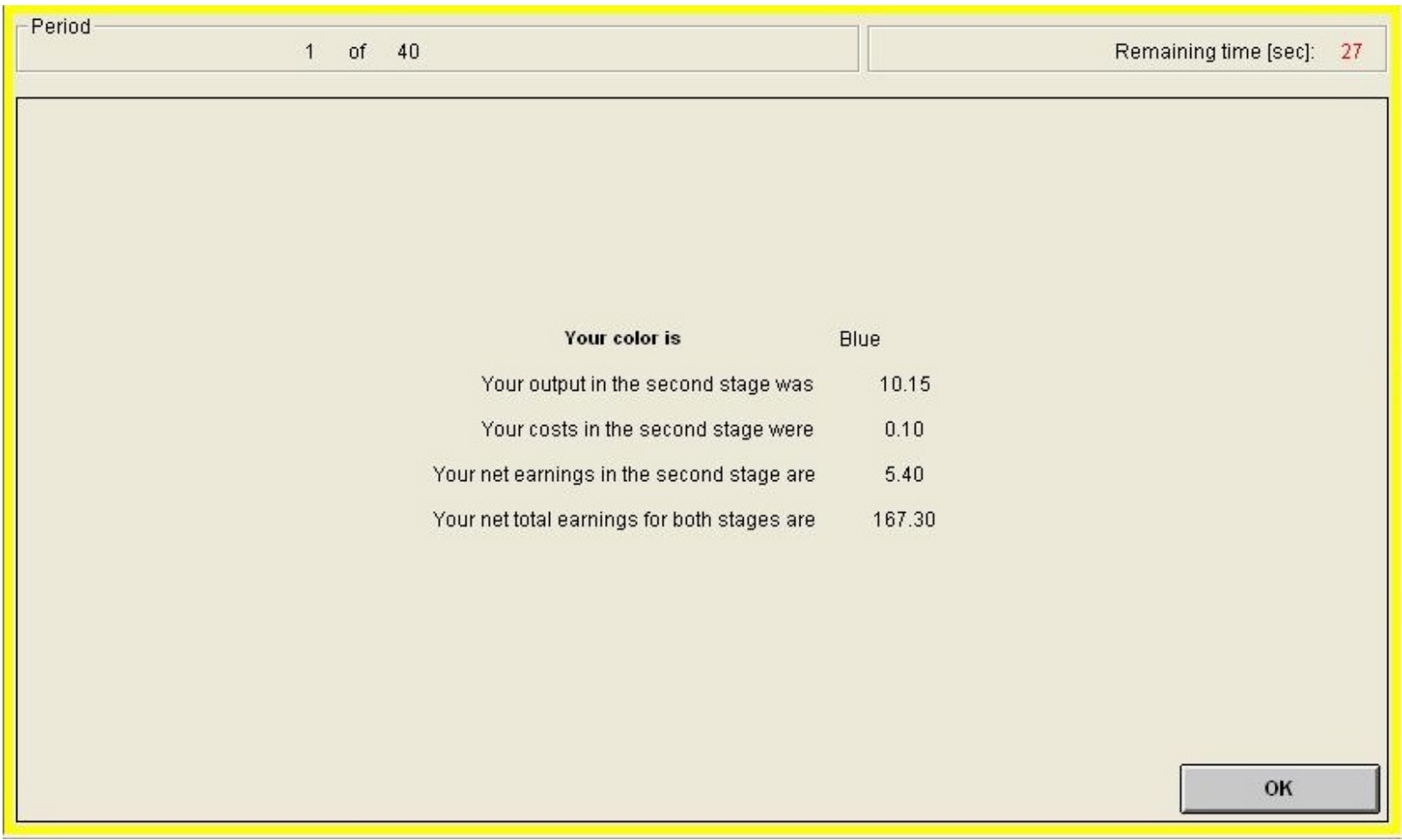

Figure A8 Post-Production Feedback 


\section{Appendix: Scales}

\section{Abbreviated 4-item Rotter Internal-External Locus of Control Scale}

A. What happens to me is my own doing.

B. Sometimes I feel that I don't have enough control over the direction my life is taking.

A. When I make plans, I am almost certain that I can make them work.

B. It is not always wise to plan too far ahead because many things turn out to be a matter of good or bad fortune.

A. In my case getting what I want has little or nothing to do with luck.

B. Many times we might just as well decide what to do by flipping a coin.

A. Many times I feel that I have little influence over the things that happen to me.

B. It is impossible for me to believe that chance or luck plays an important role in my life.

\section{HRS/NLSY79 Risk Preference}

A. Now I have another kind of question. Suppose that you are the only income earner in the family, and you have a good job guaranteed to give you your current (family) income every year for life. You are given the opportunity to take a new and equally good job, with a 50-50 chance that it will double your (family) income and a 50-50 chance that it will cut your (family) income by a third. Would you take the new job?

Yes (go to B)

No (go to $\mathrm{C}$ )

B. Suppose the chances were 50-50 that it would double your (family) income and 50-50 that it would cut it in half. Would you still take the new job?

Yes (go to end)

No (go to end)

C. Suppose the chances were 50-50 that it would double your (family) income and 50-50 that it would cut it by 20 percent. Would you take the new job?

Yes (go to end)

No (go to end)

\section{GSOEP Risk Preference}

Are you generally a person who is fully prepared to take risks or do you try to avoid taking risks? Rate yourself from 0 to 10 , where 0 means "unwilling to take any risks" and 10 means "fully prepared to take risks." 


\section{Holt-Laury Low Stakes Risk Preference}

In the questions that follow, you are going to be asked to make ten decisions. Each decision will be between Option A and Option B. Please enter your decisions below and on the corresponding sheet that was handed out to you. Only one of the ten choices you make will be used to determine your earnings for this part of the experiment. After you answer all 10 questions you will be shown the "decision selected" and "outcome" which will be used to calculate your earnings. Be sure to write these down. Each decision is a paired choice between "Option A" and "Option B." You will make ten choices. Before you start making your ten choices, let me explain what these choices mean. Imagine a ten-sided die that will be used to determine payoffs; the faces are numbered from 1 to 10. After you have made all of your choices, the die would be thrown twice, once to select one of the ten decisions to be used, and a second time to determine what your payoff is for the option you chose, A or B, for the particular decision selected. Given this, you should make the choice that you would prefer if we were throwing the die for real. Now, please look at Decision 1 at the top. Option A pays 200 pennies if the throw of the ten sided die is 1 , and it pays 160 pennies if the throw is 2-10. Option B yields 385 pennies if the throw of the die is 1 , and it pays 10 pennies if the throw is $2-10$. The other Decisions are similar, except that as you move down the table, the chances of the higher payoff for each option increase. In fact, for Decision 10 in the bottom row, the die will not be needed since each option pays the highest payoff for sure, so your choice here is between 200 pennies or 385 pennies.

To summarize, you will make ten choices: for each decision row you will have to choose between Option A and Option B. You may choose A for some decision rows and B for other rows, and you may change your decisions and make them in any order.

\begin{tabular}{|c|c|c|c|}
\hline & Option A & Option B & $\underline{\text { Your Choice }}$ \\
\hline 1. & $1 / 10$ of $\$ 2.00 \quad 9 / 10$ of $\$ 1.60$ & $1 / 10$ of $\$ 3.85 \quad 9 / 10$ of $\$ 0.10$ & A / B \\
\hline 2. & $2 / 10$ of $\$ 2.00 \quad 8 / 10$ of $\$ 1.60$ & $2 / 10$ of $\$ 3.85 \quad 8 / 10$ of $\$ 0.10$ & A / B \\
\hline 3. & $3 / 10$ of $\$ 2.00 \quad 7 / 10$ of $\$ 1.60$ & $3 / 10$ of $\$ 3.85 \quad 7 / 10$ of $\$ 0.10$ & A / B \\
\hline 4. & $4 / 10$ of $\$ 2.00 \quad 6 / 10$ of $\$ 1.60$ & $4 / 10$ of $\$ 3.85 \quad 6 / 10$ of $\$ 0.10$ & $\mathbf{A} / \mathbf{B}$ \\
\hline 5. & $5 / 10$ of $\$ 2.00 \quad 5 / 10$ of $\$ 1.60$ & $5 / 10$ of $\$ 3.85 \quad 5 / 10$ of $\$ 0.10$ & A / B \\
\hline 6. & $6 / 10$ of $\$ 2.00 \quad 4 / 10$ of $\$ 1.60$ & $6 / 10$ of $\$ 3.85 \quad 4 / 10$ of $\$ 0.10$ & A / B \\
\hline 7. & $7 / 10$ of $\$ 2.00 \quad 3 / 10$ of $\$ 1.60$ & $7 / 10$ of $\$ 3.85 \quad 3 / 10$ of $\$ 0.10$ & A / B \\
\hline 8. & $8 / 10$ of $\$ 2.00 \quad 2 / 10$ of $\$ 1.60$ & $8 / 10$ of $\$ 3.852 / 10$ of $\$ 0.10$ & $\mathbf{A} / \mathbf{B}$ \\
\hline 9. & $9 / 10$ of $\$ 2.00 \quad 1 / 10$ of $\$ 1.60$ & $9 / 10$ of $\$ 3.85 \quad 1 / 10$ of $\$ 0.10$ & A / B \\
\hline
\end{tabular}


10.

\section{$10 / 10$ of $\$ 2.00 \quad 0 / 10$ of $\$ 1.60$}

$10 / 10$ of $\$ 3.85 \quad 0 / 10$ of $\$ 0.10$

A / B

\section{LOT-R Optimism-Pessimism}

Using the response scale provided, let us know how much you agree or disagree with each of the following statements.
$\mathrm{A}=\mathrm{I}$ agree a lot
$\mathrm{B}=\mathrm{I}$ agree a little
$\mathrm{C}=\mathrm{I}$ neither agree nor disagree
$\mathrm{D}=\mathrm{I}$ disagree a little
$\mathrm{E}=\mathrm{I}$ disagree $\mathrm{a}$ lot

In uncertain times, I usually expect the best.

If something can go wrong for me, it will.

I'm always optimistic about my future.

I hardly ever expect things to go my way.

I rarely count on good things happening to me.

Overall, I expect more good things to happen to me than bad.

\section{Preference for Merit Scale}

Please indicate the extent to which you agree or disagree with each of the following statements by selecting the appropriate response from the scale below.
$\mathrm{A}=$ Strongly Agree
$\mathrm{B}=$ Moderately Agree
$\mathrm{C}=$ Slightly Agree
$\mathrm{D}=$ Neither Agree nor Disagree
$\mathrm{E}=$ Slightly Disagree
$\mathrm{F}=$ Moderately Disagree
$\mathrm{G}=$ Strongly Disagree

In work organizations, each employee ought to be named employee of the month at least once, even if he or she is not deserving.

In organizations, people who do their job well ought to rise to the top. 
It is wrong for an employee to give a job to someone they know without advertising the job to other candidates.

In life, people ought to get what they deserve.

The effort a worker puts into a job ought to be reflected in the size of a raise he or she receives. When students are working on a group project, each member of the group ought to receive the same grade regardless of the amount of effort each team member puts in.

Promotion decisions ought to take into account the effort workers put into their job.

Members of a work team ought to receive different pay depending on the amount each person contributed.

Sometimes it is appropriate to give a raise to the worker who most needs it, even if he or she is not the most hard working.

Qualifications ought to be given more weight than seniority when making promotion decisions.

Between two equally smart students applying for the same jon, the one who is the harder worker ought to always get the job.

When a bonus is given to a work team for good performance, the money ought to always be divided equally among the group members.

It is never appropriate to choose which student to hire by how much the student needs the job.

People ought to be able to get away with poor quality work under some circumstances.

If every person in an office has the same abilities, the promotion ought to always be given to the person who puts in the most effort. 